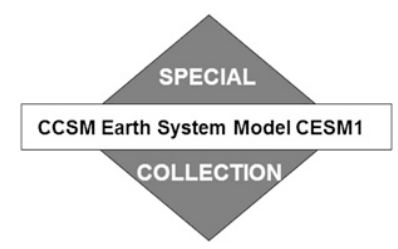

\title{
Preindustrial-Control and Twentieth-Century Carbon Cycle Experiments with the Earth System Model CESM1(BGC)
}

\author{
Keith Lindsay,* Gordon B. Bonan, ${ }^{*}$ SCOTt C. Doney, ${ }^{+}$Forrest M. Hoffman, \\ David M. LAwrence, ${ }^{*}$ Matthew C. Long, ${ }^{*}$ NAtalie M. Mahowald, ${ }^{@}$ J. Keith Moore, ${ }^{\&}$ \\ JAMES T. RANDERSON, ${ }^{\&}$ AND PETER E. THORNTON** \\ * Climate and Global Dynamics Division, National Center for Atmospheric Research, ${ }^{++}$Boulder, Colorado \\ ${ }^{+}$Department of Marine Chemistry and Geochemistry, Woods Hole Oceanographic Institution, Woods Hole, Massachusetts \\ ${ }^{\#}$ Computational Earth Sciences Group, Oak Ridge National Laboratory, Oak Ridge, Tennessee \\ ${ }^{\circledR}$ Department of Earth and Atmospheric Sciences, Cornell University, Ithaca, New York \\ ${ }^{\&}$ Department of Earth System Science, University of California, Irvine, Irvine, California \\ ** Environmental Sciences Division and Climate Change Science Institute, Oak Ridge National Laboratory, \\ Oak Ridge, Tennessee
}

(Manuscript received 31 July 2012, in final form 25 July 2014)

\begin{abstract}
Version 1 of the Community Earth System Model, in the configuration where its full carbon cycle is enabled, is introduced and documented. In this configuration, the terrestrial biogeochemical model, which includes carbonnitrogen dynamics and is present in earlier model versions, is coupled to an ocean biogeochemical model and atmospheric $\mathrm{CO}_{2}$ tracers. The authors provide a description of the model, detail how preindustrial-control and twentieth-century experiments were initialized and forced, and examine the behavior of the carbon cycle in those experiments. They examine how sea- and land-to-air $\mathrm{CO}_{2}$ fluxes contribute to the increase of atmospheric $\mathrm{CO}_{2}$ in the twentieth century, analyze how atmospheric $\mathrm{CO}_{2}$ and its surface fluxes vary on interannual time scales, including how they respond to ENSO, and describe the seasonal cycle of atmospheric $\mathrm{CO}_{2}$ and its surface fluxes. While the model broadly reproduces observed aspects of the carbon cycle, there are several notable biases, including having too large of an increase in atmospheric $\mathrm{CO}_{2}$ over the twentieth century and too small of a seasonal cycle of atmospheric $\mathrm{CO}_{2}$ in the Northern Hemisphere. The biases are related to a weak response of the carbon cycle to climatic variations on interannual and seasonal time scales and to twentieth-century anthropogenic forcings, including rising $\mathrm{CO}_{2}$, land-use change, and atmospheric deposition of nitrogen.
\end{abstract}

\section{Introduction}

Climate models based on atmospheric and ocean general circulation models have been used as tools in recent decades to aid our understanding of Earth's climate. As research has advanced, these models have become progressively more sophisticated by including more processes and feedbacks and by being run at finer spatial resolution. The terminology related to these

\footnotetext{
${ }^{++}$The National Center for Atmospheric Research is sponsored by the National Science Foundation.

Corresponding author address: Keith Lindsay, NCAR, P.O. Box 3000, Boulder, CO 80307.

E-mail: klindsay@ucar.edu
}

models has also evolved, with some classes of models now being referred to as Earth system models.

While this term does not have a uniformly accepted definition, models that couple a prognostic carbon cycle model to a climate model are generally agreed to qualify as Earth system models. These models can predict atmospheric $\mathrm{CO}_{2}$, allowing for internally consistent feedbacks between the varying model climate and atmospheric $\mathrm{CO}_{2}$. This is in contrast to traditional climate models that use prescribed atmospheric $\mathrm{CO}_{2}$ trajectories that are produced by an independent, and typically reduced-complexity, model. Usage of such earth system models is becoming more widespread (Friedlingstein et al. 2006; Arora et al. 2013), and efforts to establish benchmarks quantifying model reliability are ongoing (Randerson et al. 2009; Cadule et al. 2010; Anav et al. 2013; Hoffman et al. 2014). 
Models of this class play a larger role in the fifth assessment report of the Intergovernmental Panel on Climate Change (IPCC) than they have in previous reports, primarily through their application to experiments that comprise phase 5 of the Coupled Model Intercomparison Project (CMIP5). This manuscript documents preindustrial-control and twentieth-century experiments performed with version 1 of the Community Earth System Model (CESM1) (Hurrell et al. 2013) with the full carbon cycle enabled. In this configuration, the terrestrial biogeochemical model, which includes carbonnitrogen dynamics and is present in earlier model versions, is coupled to an ocean biogeochemical model and atmospheric $\mathrm{CO}_{2}$ tracers. The development of this model has followed the pattern alluded to above, where publicly supported configurations of previous model versions, the Climate System Model (CSM) and the Community Climate System Model (CCSM), did not include a full carbon cycle. While previous studies (Fung et al. 2005; Doney et al. 2006; Thornton et al. 2009) have described the coupling of biogeochemical models encompassing the carbon cycle to CSM and CCSM, these studies have used coarser-resolution configurations than were used for CMIP experiments, and the coupled models have not had fully supported public releases.

The outline of this manuscript is as follows. In section 2, we describe CESM1, focusing on the biogeochemical parameterizations and aspects of the climate model that are particularly relevant to biogeochemistry. We describe in section 3 the preindustrial-control and twentiethcentury experiments that we are documenting, the forcings used, and how the experiments have been initialized. In section 4, we present and discuss the results of these experiments. We summarize the results in section 5 and present conclusions.

\section{Model description}

CESM1 was publicly released in June 2010 (Hurrell et al. 2013). This model supersedes version 4 of the Community Climate System Model (CCSM4) and offers several new scientific capabilities beyond those of CCSM4, including a biogeochemical model, an atmospheric chemistry package, a version of the atmospheric model that extends further into the upper atmosphere, a dynamic ice sheet model, and significant enhancements to the atmospheric physics parameterizations. This manuscript documents experiments with the biogeochemical model enabled, a configuration denoted CESM1(BGC). The only differences between this configuration and CCSM4 are the introduction of an ocean biogeochemical model and three-dimensional atmospheric $\mathrm{CO}_{2}$ tracers, as well as the interactive coupling of these components to each other and the preexisting land biogeochemical model. In addition to enabling scientific experiments with an interactive carbon cycle that is coupled to the climate model, these new capabilities introduce additional feedbacks of the biogeochemistry onto the physical climate.

The ocean biogeochemical model affects the physical climate by providing surface chlorophyll concentrations which determine the depth profile of absorption of shortwave radiation in the ocean. This feedback can be disabled, reverting to the CCSM4 behavior, where the depth profile of absorption is determined by a fixed monthly climatology of satellitederived surface chlorophyll concentrations. This feedback is enabled for all experiments documented in this manuscript.

The three-dimensional atmospheric $\mathrm{CO}_{2}$ tracers, which are forced by sea- and land-to-air $\mathrm{CO}_{2}$ fluxes, affect the physical climate by providing the atmospheric $\mathrm{CO}_{2}$ used in both atmospheric radiative transfer computations and terrestrial photosynthesis computations. Terrestrial photosynthesis affects the physical climate through its coupling to the hydrologic and energy cycles. These feedbacks of the $\mathrm{CO}_{2}$ tracers onto radiation and terrestrial photosynthesis can be enabled independently of each other. When they are disabled, the model reverts to the CCSM4 behavior, where the atmospheric $\mathrm{CO}_{2}$ used in the computations is prescribed and is spatially uniform. The atmospheric $\mathrm{CO}_{2}$ tracers can also be used in the sea-to-air gas flux computations, though these fluxes do not directly affect the physical climate. In the remainder of the manuscript, we refer to computations of radiative transfer, terrestrial photosynthesis, and sea-to-air gas flux collectively as $\mathrm{CO}_{2-}$ related computations.

We describe below these new features of CESM1(BGC) and aspects of CCSM4 that are particularly relevant to biogeochemical parameterizations. Further aspects of CCSM4 are documented in Gent et al. (2011).

All experiments documented in this manuscript were run at a fixed resolution, the resolution denoted as $1^{\circ}$ by Gent et al. (2011). Briefly, the atmospheric grid has 26 vertical layers and a horizontal resolution of $1.25^{\circ} \times$ $0.94^{\circ}$. The land model uses the same horizontal grid as the atmospheric model, though each grid cell is decomposed into portions that have distinct prescribed land types (e.g., vegetated, urban, lake, etc.). The ocean model uses a nonuniform grid, where the northern pole is displaced into Greenland. The grid has a zonal resolution of $1.125^{\circ}$ and a meridional resolution that varies from $0.27^{\circ}$ near the equator to $0.53^{\circ}$ in the extratropics. The vertical grid is nonuniform and has 60 layers. The layer thicknesses are $10 \mathrm{~m}$ in the top $150 \mathrm{~m}$, increase with 
depth, and are $250 \mathrm{~m}$ below $4000 \mathrm{~m}$. The sea ice model uses the same horizontal grid as the ocean model.

\section{a. Ocean biogeochemical model}

The ocean biogeochemical model, based on the model of Moore et al. (2004) and documented in Moore et al. (2013), follows the nutrient-phytoplankton-zooplanktondetritus (NPZD) paradigm of ocean ecosystem modeling. The ecosystem component of the model includes three full phytoplankton functional types (diatoms, pico/nano phytoplankton, and diazotrophs), a partial calcifier class, and a single adaptive zooplankton class. Phytoplankton growth is controlled by temperature, light, and available nutrients $(\mathrm{N}, \mathrm{P}, \mathrm{Si}, \mathrm{Fe})$. While the model assumes fixed $\mathrm{C}: \mathrm{N}: \mathrm{P}$ ratios for each functional group, $\mathrm{C}: \mathrm{Fe}$ and $\mathrm{C}: \mathrm{Si}$ ratios are allowed to vary in response to available nutrients. The full carbonate system is utilized to compute seato-air $\mathrm{CO}_{2}$ gas exchange. The model uses the fixed climatology of Luo et al. (2003) for atmospheric deposition of dust and iron and incorporates the work of Moore and Braucher (2008), who added an improved sedimentary iron source and scavenging parameterization. The model includes atmospheric deposition of nitrogen, which is shown by Krishnamurthy et al. (2007) to be an important source of nitrogen to the euphotic zone. For the experiments documented in this manuscript, the model uses the time-varying nitrogen deposition fields of Lamarque et al. (2010), adjusted to account for the fact that the ocean biogeochemical model does not include emissions of nitrogen from the ocean.

Sinking particulate organic matter (POM) is divided into two classes: POM associated with sinking mineral ballast materials; and "soft" POM not associated with ballast. The large majority of sinking POM leaving the euphotic zone is soft POM ( $\sim 95 \%)$, and it remineralizes with depth according to a prescribed exponential decay with an associated length scale. The ballasted POM remineralizes deeper in the water column according to the prescribed remineralization curve for the different ballast materials (dust, biogenic silica, and calcium carbonate). Thus, the fraction of ballasted POM increases with depth. This approach, which follows that suggested by Armstrong et al. (2001), is described in more detail by Moore et al. (2004).

When the biogeochemical model was initially coupled to the simulated ocean circulation of CCSM4 (Gent et al. 2011; Danabasoglu et al. 2012), it developed excessively large subsurface oxygen minimum zones (OMZs). The global volume of water with $\mathrm{O}_{2}$ less than $20 \mu \mathrm{mol} \mathrm{L}^{-1}$ in the model is $3.7 \times 10^{16} \mathrm{~m}^{3}$, compared to $1.3 \times 10^{16} \mathrm{~m}^{3}$ in the analyzed product of Garcia et al. (2010). This feature in the model is due to excessive remineralization of organic matter in the OMZs relative to how vigorously the circulation ventilates the OMZs. A consequence of the large OMZs is an imbalance in the simulated global ocean nitrogen budget. This is because remineralization of organic matter in anoxic regions, defined by the condition $\mathrm{O}_{2}<4 \mu \mathrm{mol} \mathrm{L}{ }^{-1}$, causes denitrification, a process that consumes nitrate (Moore and Doney 2007). To avoid an unrealistic loss of nitrate, we artificially scale model predicted denitrification by $\mathrm{NO}_{3} / 110$, where $\mathrm{NO}_{3}$ is the model predicted nitrate concentration in units of $\mu \mathrm{mol} \mathrm{L}^{-1}$. Note that this scaling only reduces the denitrification; it does not reduce the size of the OMZs.

\section{b. Land biogeochemical model}

Version 4 of the Community Land Model (CLM4) is the land component of CCSM4 and CESM1. Lawrence et al. (2011) describe the model, and D. M. Lawrence et al. (2012) document its coupling with the climate model. The land model simulates biogeophysical exchanges of shortwave and longwave radiation, momentum, and turbulent fluxes (sensible heat and latent heat) between land and atmosphere as modified by vegetation and soil; heat transfer in soil and snow; and the hydrologic cycle, including interception of precipitation by vegetation, infiltration, surface and subsurface runoff, soil water redistribution, water table depth, and snow dynamics. Evapotranspiration is partitioned into evaporation of intercepted water, transpiration, and soil evaporation. Transpiration is regulated by stomatal physiology and photosynthesis.

The CLM4 includes a prognostic biogeochemical model with carbon-nitrogen dynamics coupled to the biogeophysics and hydrology (CLM4CN; Thornton et al. 2007, 2009). The model simulates carbon and nitrogen state variables in vegetation, litter, and soil organic matter. Vegetation is represented by leaf, fine root, respiring and nonrespiring stem and coarse root, and storage pools. Leaf phenology is simulated for an evergreen type, for which some fraction of annual leaf growth persists in the displayed pool for longer than one year; a seasonal-deciduous type with a single growing season per year, controlled mainly by temperature and daylength; and a stress-deciduous type with the potential for multiple growing seasons per year, controlled by temperature and soil moisture conditions. The heterotrophic model represents coarse woody debris, three litter pools, and four soil organic matter pools. A prognostic fire model simulates wildfire. For the experiments documented in this manuscript, CLM4CN uses the timevarying deposition fields of Lamarque et al. (2010) for atmospheric deposition of nitrogen.

The spatial distribution of plant functional types (PFTs) is prescribed, using the datasets of Hurtt et al. 
(2006). This prescription of PFTs precludes competition between PFTs for light, while allowing for competition for moisture and nitrogen. We note that while CESM1 includes the functionality of including seasonal crop phenology (Levis et al. 2012), this is not utilized in our experiments. Crop PFTs in our experiments are treated as unmanaged grasslands. Details of how the model incorporates transient land-cover and land-use change, including wood harvest, are described by P. J. Lawrence et al. (2012). Land-cover change is specified for each grid cell through annual changes in the fractional area of PFTs. The model diagnoses the change in PFT area and adjusts carbon pools for mass conservation. When PFT area decreases, lost mass is distributed among litter, wood products, and a land-cover conversion flux that is released immediately to the atmosphere. When PFT area increases, vegetation carbon density is reduced to conserve vegetation carbon mass. A portion of the wood carbon is transferred to product pools, which are released to the atmosphere with 10-yr and 100-yr lifespans. Wood harvest is specified as the annual removal of a percentage of trees, based on the datasets of Hurtt et al. (2006). Harvesting is implemented similarly to landcover change, except that it does not change PFT composition and instead removes a specified fraction of the vegetation mass.

\section{c. Atmospheric $\mathrm{CO}_{2}$ tracers}

$\mathrm{CO}_{2}$ fluxes computed by the ocean and land models provide surface flux boundary conditions for the threedimensional $\mathrm{CO}_{2}$ tracers in the atmosphere. The sea-toair fluxes are updated daily, and the land-to-air fluxes are updated half-hourly. The atmospheric model also uses prescribed anthropogenic $\mathrm{CO}_{2}$ surface fluxes. We refer to these fluxes as fossil fuel emissions, though they have other industrial sources, such as cement production. There is an atmospheric tracer for each of these surface fluxes (ocean, land, and fossil fuel) that uses that flux as a surface boundary condition and one net $\mathrm{CO}_{2}$ tracer that uses the sum of all of the surface fluxes as a surface boundary condition. These tracers are transported by the atmospheric model as dry mass mixing ratios.

When $\mathrm{CO}_{2}$ tracers are used in atmospheric radiative transfer computations, the column average of the net $\mathrm{CO}_{2}$ tracer is used. When $\mathrm{CO}_{2}$ tracers are used in terrestrial photosynthesis and sea-to-air flux computations, the net $\mathrm{CO}_{2}$ tracer in the bottom layer is used.

\section{Experiment description}

We document in this manuscript results from preindustrial-control and twentieth-century (18502005) experiments, which we denote as 1850 and 20C experiments, respectively. For brevity, in places we refer to the 1850 experiments as the controls. Except for the addition of fossil fuel emissions and forcings necessary for the ocean biogeochemical model, the forcings for these experiments are unchanged from CCSM4. As described in Gent et al. (2011), the transient forcings for the $20 \mathrm{C}$ experiments include greenhouse gases, radiatively active aerosols (anthropogenic and natural, including volcanoes), aerosol deposition to surface components (e.g., black carbon on snow), land-use change (including harvest), anthropogenic nitrogen deposition, and solar variability. These forcings are held fixed at their 1850 values, or climatologies, in the controls. For fossil fuel emissions of $\mathrm{CO}_{2}$, the $20 \mathrm{C}$ experiments use a preliminary version of the standard CMIP5 dataset, which is a gridded dataset with monthly resolution. Fossil fuel emissions of $\mathrm{CO}_{2}$ are set to zero in the controls.

Experiments were run with two $\mathrm{CO}_{2}$ options, prescribed (PRES) and prognostic (PROG). In the PRES experiments, $\mathrm{CO}_{2}$-related computations use prescribed spatially uniform values. In the PROG experiments, they use the prognostic three-dimensional atmospheric $\mathrm{CO}_{2}$ tracers. All of the experiments have prognostically computed atmospheric $\mathrm{CO}_{2}$ tracers. In the PRES experiment, these tracers do not affect radiative or biogeochemical computations. We note that the PRES experiments differ from corresponding CCSM4 experiments documented in Gent et al. (2011) only by the effect of prognostic surface chlorophyll on the vertical distribution of shortwave absorption in the ocean.

Experiments were run for all pairs of forcing (1850 and 20C) and $\mathrm{CO}_{2}$ options, yielding four experiments: 1850 PRES, 1850 PROG, 20C PRES, and 20C PROG. A single ensemble member of each $20 \mathrm{C}$ configuration has been run.

The atmospheric nitrogen deposition dataset used by the ocean model was updated at the beginning of years 301 and 101 of the PROG and PRES controls, respectively, to correct a bug in the offline processing of the Lamarque et al. (2010) forcing. The effect of this correction on the results of the experiments was very small.

\section{Initialization}

Except for ocean biogeochemical tracers and the land state, the initial state of the CESM1(BGC) controls was based on the initial state of the CCSM4 control. The initialization procedure used for the CCSM4 control is documented in Gent et al. (2011).

The initial state of the ocean biogeochemical tracers was generated by adding these tracers to a preliminary version of CCSM4 and directly spinning them up, yielding a tracer state in approximate balance with the modeled ocean circulation of CCSM4. To reduce the 
computational cost of the spin-up experiment, the active atmospheric model was replaced with a data-reading component that repeatedly cycled through $5 \mathrm{yr}$ of highfrequency surface forcing that were extracted from a fully coupled experiment. The ocean physical state for the spinup was initialized with the ocean state of the coupled experiment at the beginning of the 5-yr cycle. To avoid drift of the ocean physical state, it was reset to its initial condition at the beginning of each 5-yr cycle, keeping it synchronized with the surface forcing. The prognostic chlorophyll option of CESM1(BGC) was turned off in this spinup experiment, in order to be consistent with CCSM4 physics. The atmospheric $\mathrm{CO}_{2}$ used in sea-to-air $\mathrm{CO}_{2}$ flux computations was the 1850 reference value, $284.7 \mathrm{ppmv}$. The spin-up experiment was run for 1025 years. At year 900, the ocean was outgassing carbon at a rate of $\sim 0.15 \mathrm{PgC} \mathrm{yr}^{-1}$. To reduce this, the remineralization-length scale for unballasted sinking POM was increased from 200 to $210 \mathrm{~m}$ at year 915. With this change, the outgassing was reduced to $\sim 0.06 \mathrm{Pg} \mathrm{Cyr}^{-1}$ at year 1025 . A preferable approach to reduce the outgassing is to have a longer spinup. However, computer resources were not available to do this. This increased length scale has been used in all subsequent experiments and is the default in CESM1(BGC). Ocean biogeochemical tracers were initialized in the first CESM1(BGC) experiments with their values from the start of year 1026 in the ocean spinup.

The initial state for the land model was set to the land state from the start of year 863 of the CCSM4 control. The land model in that experiment was initialized with the results of a 690-yr land spin-up experiment that was forced with $30 \mathrm{yr}$ of repeat surface forcing extracted from the same experiment that was used for forcing data for the ocean spinup. The atmospheric nitrogen deposition dataset used by the land model was updated at the beginning of year 715 of the CCSM4 control to correct a bug. This change induced a drift of $\sim 0.023 \mathrm{Pg} \mathrm{Cyr}^{-1}$ in the land carbon inventory over years $800-1300$ of that control experiment.

These model component states were used for an initial CESM1(BGC) experiment that used prognostic atmospheric $\mathrm{CO}_{2}$ for the computation of surface carbon fluxes. The atmospheric $\mathrm{CO}_{2}$ tracers in this experiment were initialized to the 1850 reference value, and atmospheric radiative transfer computations used the 1850 reference value. The objective of this experiment was to allow the surface biogeochemical parameterizations to adjust to the prognostic $\mathrm{CO}_{2}$ and to allow the nearsurface ocean biogeochemical tracers to adjust to the full spectrum of interannually varying circulation, as opposed to just the 5-yr segment with which they were spun up. This experiment was run for 120 years and found to have small drifts in the ocean and land carbon inventories. Subsequently, the PROG control, which includes the use of $\mathrm{CO}_{2}$ tracers for atmospheric radiative transfer computations, was initialized from this intermediate experiment, using the physical and biogeochemical model state from the start of year 51. The PRES control used the same initial conditions as the PROG control.

Both control experiments were run for 1000 years. The 20C PROG experiment branched from the PROG control at the beginning of year 351. The 20C PRES experiment branched from the PRES control at the beginning of year 151 .

\section{Results and discussion}

\section{a. Physical climate}

The modeled biogeochemical cycles in CESM1(BGC) are sensitive to the modeled physical climate system, so it is important to understand the behavior of the modeled climate in order to put the modeled biogeochemistry into context. The core atmosphere, ocean, and land models are very similar between CCSM4 and CESM1(BGC), differing only with the introduction of prognostic chlorophyll in the ocean in the PRES experiments, which affects the vertical distribution of shortwave absorption, and the additional introduction of prognostic $\mathrm{CO}_{2}$ in the PROG experiments, which affects radiative transfer and terrestrial photosynthesis computations. Because of the relatively small effect of these changes on the physical climate system (see Table 1), we can rely on detailed prior analysis, which we summarize briefly here, of the CCSM4 climate [see Gent et al. (2011); D. M. Lawrence et al. (2012); Danabasoglu et al. (2012); and other articles from the J. Climate CCSM4 special collection].

In general, the CCSM4 climate simulation is better than it is in CCSM3. The sea surface temperature simulation is improved in all oceans except the Arctic Ocean. Cold biases in the North Atlantic are substantially reduced. Warm biases in the major upwelling regions and cold biases in Southern Hemisphere midlatitudes remain problematic in CCSM4 (Gent et al. 2011). Over land, biases in the amplitude of the surface (2-m) air temperature $\left(T_{\text {air }}\right)$ annual cycle at northern high latitudes that are prevalent in CCSM3 are substantially reduced, which contributes to an overall $\sim 20 \%$ reduction in centered RMSE in CCSM4 compared to CCSM3. The centered RMSE is calculated by taking the RMSE of the climatological seasonal cycle after removing the annual mean.

Across most of the tropics, mean annual biases are less than $2^{\circ} \mathrm{C}$. The worst $T_{\text {air }}$ bias over land is a swath of 
TABLE 1. Summary of CESM1(BGC) 1850 differences from CCSM4 1850. CCSM4 values are from annual means averaged over years 171-370. CESM1(BGC) values are from annual means averaged over years 121-320. PROG and PRES refer to CESM1(BGC) experiments described in section 3. Fields include the surface (2-m) air temperature, the downwelling shortwave flux at the surface (FSDS), SST, depth of the mixed layer in the ocean (MLD), and precipitation.

\begin{tabular}{|c|c|c|c|c|c|c|c|}
\hline \multirow[b]{2}{*}{ Field } & \multirow[b]{2}{*}{ Domain } & \multirow[b]{2}{*}{ Units } & \multirow{2}{*}{$\begin{array}{c}\text { CCSM4 } \\
\text { Mean }\end{array}$} & \multicolumn{2}{|c|}{ PRES - CCSM4 } & \multicolumn{2}{|c|}{ PROG - CCSM4 } \\
\hline & & & & Mean & RMS & Mean & RMS \\
\hline$T_{\text {air }}$ & Global & $\mathrm{K}$ & 286.57 & -0.022 & 0.093 & -0.034 & 0.102 \\
\hline FSDS & Global & $\mathrm{W} \mathrm{m}^{-2}$ & 192.81 & 0.078 & 0.914 & 0.042 & 0.935 \\
\hline SST & Ocean & ${ }^{\circ} \mathrm{C}$ & 18.066 & -0.011 & 0.082 & -0.014 & 0.080 \\
\hline MLD & Ocean & $\mathrm{m}$ & 65.51 & -0.34 & 2.75 & -0.36 & 2.78 \\
\hline$T_{\text {air }}$ & Land & $\mathrm{K}$ & 280.63 & -0.031 & 0.099 & -0.059 & 0.117 \\
\hline Precipitation & Land & $\mathrm{mm} \mathrm{day}^{-1}$ & 2.368 & -0.014 & 0.079 & -0.015 & 0.079 \\
\hline
\end{tabular}

warm anomalies that exceed $4^{\circ} \mathrm{C}$ extending from Europe across central Asia (Gent et al. 2011; D. M. Lawrence et al. 2012). For precipitation, there is a wet bias at northern high latitudes in both CCSM3 and CCSM4, which leads to snow depths that are too deep, thereby preventing the ground from cooling as much as it should during winter.

The CCSM3 dry biases in wet season precipitation in the Amazon region and Indian monsoon rainfall are reduced in CCSM4. Globally, the mean precipitation bias is larger in CCSM4 than in CCSM3 as a result of bigger wet biases in Australia and central and southern Africa. Averaged over the global land area, the centered RMSE is lower by about $5 \%$ in CCSM4, which indicates a marginal improvement in the phase and amplitude of the annual cycle of precipitation. CCSM4 exhibits more realistic extreme precipitation statistics over tropical land, particularly for higher simulated peak precipitation rates (Gent et al. 2011).

The surface downwelling shortwave radiation bias pattern largely mirrors the precipitation bias pattern. Though improved over CCSM3, low biases of between -20 and $-40 \mathrm{~W} \mathrm{~m}^{-2}$ are still apparent for tropical Africa and much of the tropical ocean regions in CCSM4. Summertime high biases of +30 to $+50 \mathrm{~W} \mathrm{~m}^{-2}$ are seen over the European and central Asia region, which also exhibits a warm $T_{\text {air }}$ bias. Significant high biases are also apparent over eastern North America. A low bias in downwelling shortwave radiation at northern high latitudes in summer is substantially reduced in CCSM4.

Over long time scales, drift in the modeled climate also plays a role in the experiments. This drift in both CESM1(BGC) controls is very similar to drift in the CCSM4 control. For instance, in the CESM1(BGC) PRES and PROG controls, the model is losing heat at the top of the atmosphere at a rate of 0.145 and $0.142 \mathrm{~W} \mathrm{~m}^{-2}$, respectively, averaged over years $401-$ 1000. These values are very similar to the $0.147 \mathrm{~W} \mathrm{~m}^{-2}$ value reported in Gent et al. (2011) for years 601-1300 of the CCSM4 control.

\section{b. Carbon balance in the CESM1(BGC) controls}

Because of the procedure used to initialize the CESM1(BGC) controls, the drift in carbon inventories in the ocean, land, and atmosphere reservoirs is small (Table 2; Fig. 1).

For the ocean reservoir, while the overall decrease in inventory is similar in the two controls, it is visually apparent that the inventory has greater variability in the PROG control than in the PRES control (Fig. 1a). This increased variability is induced by the prognostic atmospheric $\mathrm{CO}_{2}$ that is used in the sea-to-air $\mathrm{CO}_{2}$ flux computations.

For the land reservoir, the drift in the controls is essentially a continuation of the drift in the CCSM4 control, as the terrestrial carbon pools come into better balance with the modeled climate (Fig. 1b). Because of the multidecadal and multicentennial variability in the time series, the drift values given in Table 2 are sensitive to the period over which the drift is computed.

In both control experiments, the overall ocean $\mathrm{CO}_{2}$ release exceeds the overall land $\mathrm{CO}_{2}$ uptake, leading to an accumulation of carbon in the atmosphere (Fig. 1c). Note that for the PRES control, this inventory is purely diagnostic; the corresponding $\mathrm{CO}_{2}$ does not affect

TABLE 2. Reservoir carbon inventory drift in 1850 experiments. Unless otherwise noted, values are from CESM1(BGC) experiments. Drift, computed as the slope of the least squares linear fit of annual mean inventory to time, has units $\mathrm{PgC}^{-1}$. The first year spans for the CESM1(BGC) experiments are 300-yr segments roughly centered about the segments coinciding with the corresponding 20C experiments. These values are used for drift correction of $20 \mathrm{C}$ uptake estimates.

\begin{tabular}{lcccc}
\hline \hline Experiment & Year span & Ocean & Land & Atmosphere \\
\hline CCSM4 & $1001-1300$ & & 0.021 & \\
PRES & $76-375$ & -0.023 & 0.004 & 0.019 \\
PROG & $276-576$ & -0.024 & 0.016 & 0.007 \\
PRES & $401-1000$ & -0.019 & 0.008 & 0.011 \\
PROG & $401-1000$ & -0.010 & 0.008 & 0.002 \\
\hline
\end{tabular}



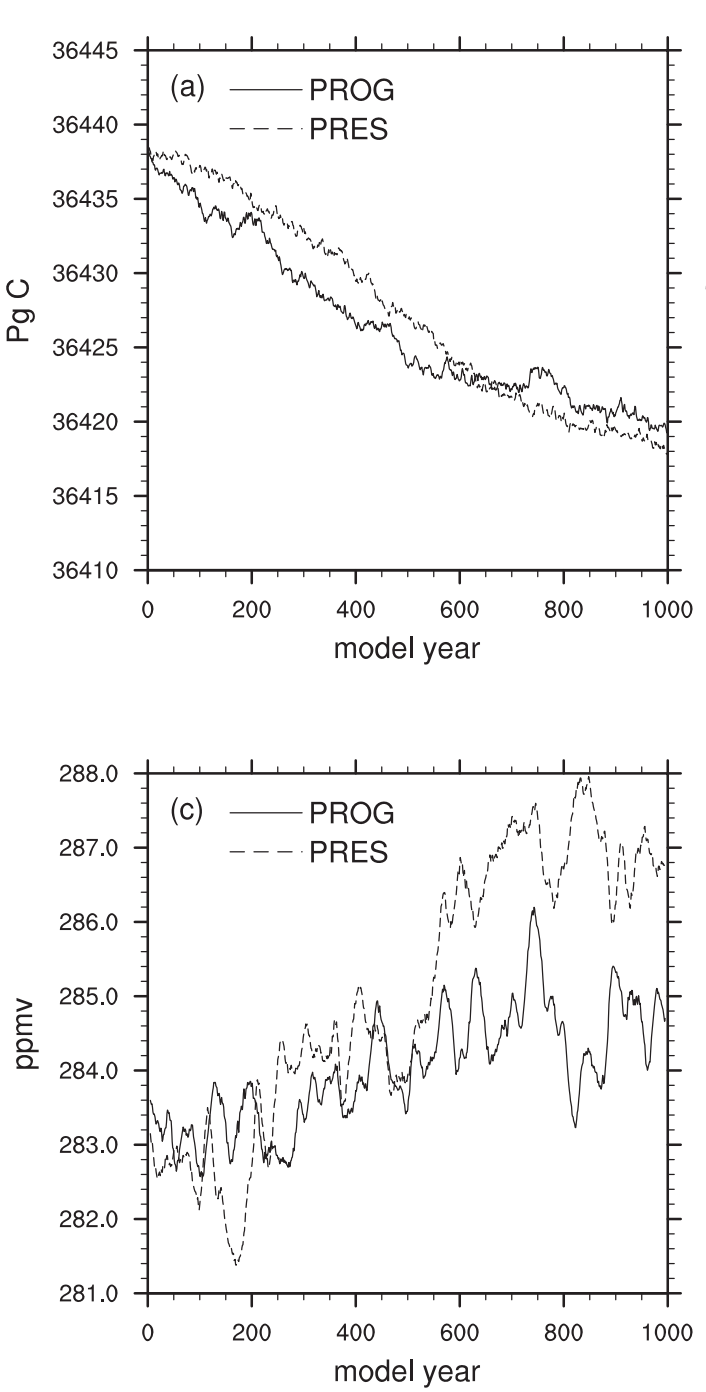

$\mathrm{CO}_{2}$-related computations. This lack of feedback, particularly on the sea-to-air fluxes, permits the atmospheric carbon inventory to drift more in the PRES control.

\section{c. Carbon sources and sinks in the twentieth-century experiments}

In this subsection, we summarize the behavior of the global carbon cycle in the 20C PRES and PROG experiments, presenting mean surface atmospheric $\mathrm{CO}_{2}$ and mean sources and sinks of $\mathrm{CO}_{2}$ into and out of the atmosphere.

To put the carbon cycle results in context, we first present the response of $T_{\text {air }}$ to the 20C forcing. With few exceptions, the response of $T_{\text {air }}$ in the CESM1(BGC) experiments is within the CCSM4 response envelope (Fig. 2a). This is not surprising for the 20C PRES

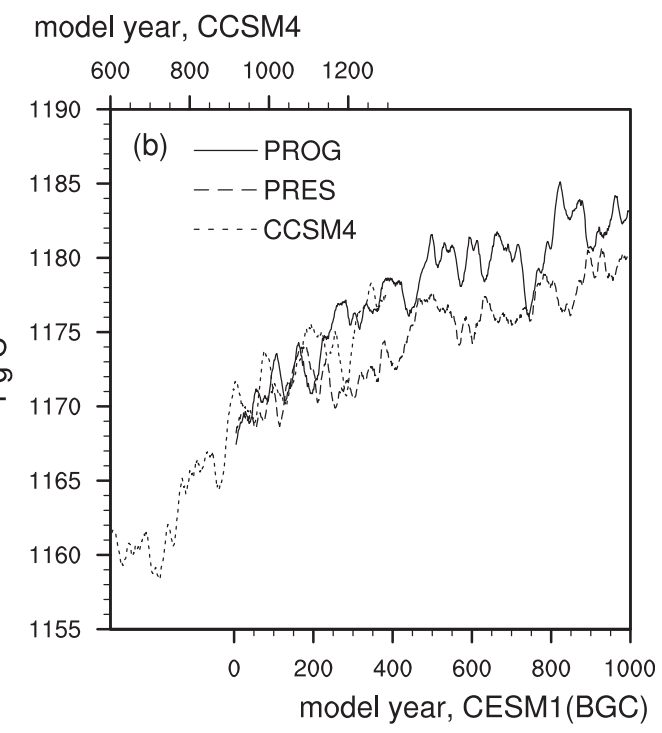

FIG. 1. Time series of (a) ocean, (b) land, and (c) atmosphere carbon inventory in 1850 controls. PROG and PRES refer to CESM1(BGC) experiments described in section 3. Time axes in (b) are aligned to depict the correspondence of year 1 of the CESM1(BGC) controls to year 913 of the CCSM4 control. Annual mean values are depicted in (a). Annual mean values, filtered with a 10-point boxcar filter to remove interannual variability, are depicted in (b) and (c). Values in (c) have been converted to the equivalent volume mixing ratio using the model's conversion factor of $2.113386 \mathrm{Pg} \mathrm{C} \mathrm{ppmv}^{-1}$.

experiment, given that the physical components of CESM1(BGC) are nearly the same as those of CCSM4 and that the transient forcing in all of these experiments is identical. The response in the CESM1(BGC) 20C PROG experiment is also within the CCSM4 envelope, even though, as we will see below, the atmospheric $\mathrm{CO}_{2}$ in this experiment is higher than observed. The enhanced heating from this higher $\mathrm{CO}_{2}$ is not large enough to yield a response in $T_{\text {air }}$ outside the CCSM4 envelope. The warming in the CCSM4 and CESM1(BGC) $20 \mathrm{C}$ experiments exceeds the warming in the Hadley Centre/ Climatic Research Unit, version 3 (HadCRUT3), observationally based dataset (Brohan et al. 2006). Gent et al. (2011) discusses possible reasons for this discrepancy, including the model's omission of the indirect effects of aerosols. 

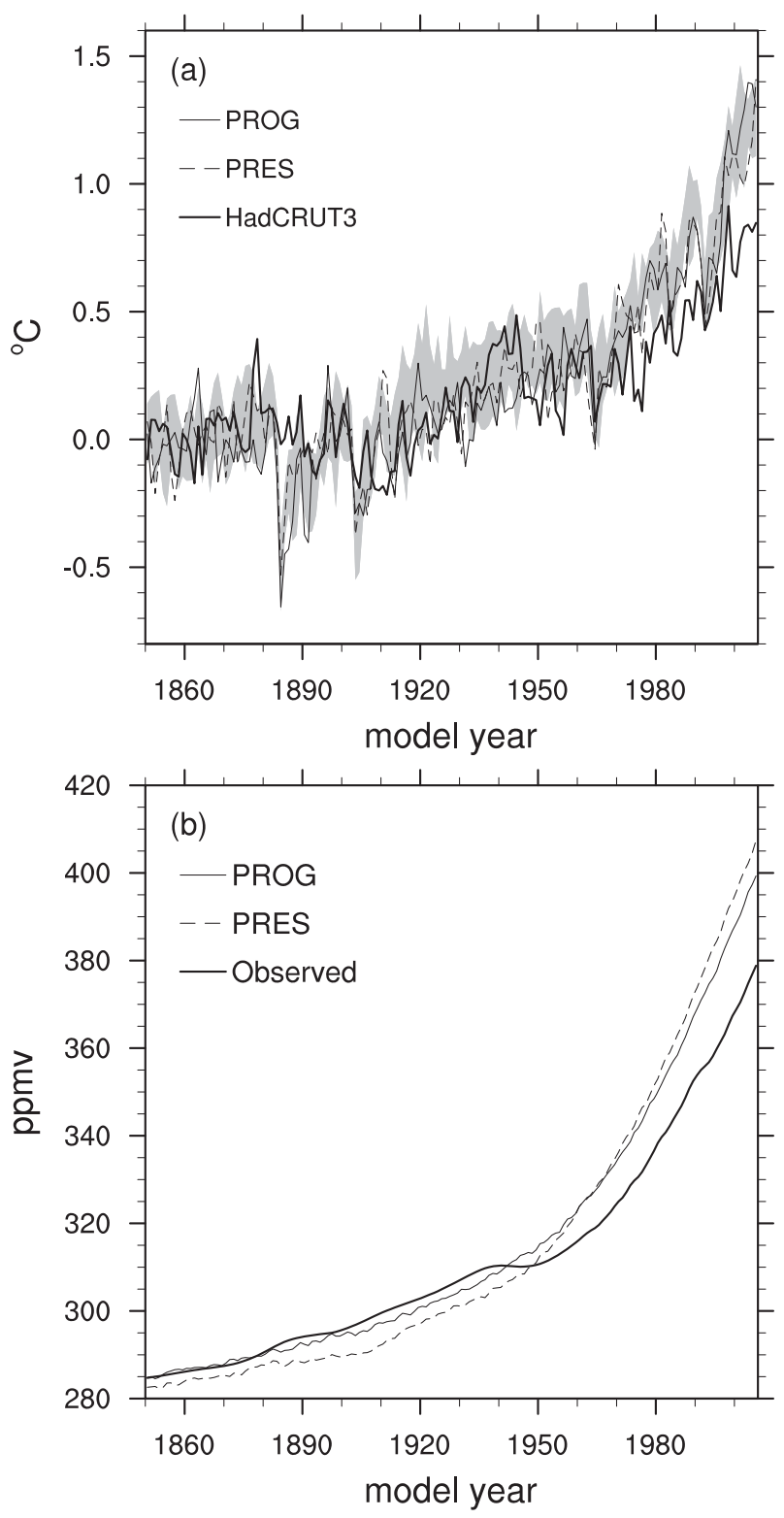

FIG. 2. Time series of 20C (a) 2-m air temperature anomalies and (b) surface net $\mathrm{CO}_{2}$ tracer. PROG and PRES refer to CESM1(BGC) experiments described in section 3. Depicted values are global averages of annual means. Anomalies in (a) are relative to the mean over the first 20 years. Shading in (a) denotes maximum and minimum anomalies over seven CCSM4 20C ensemble members. Observations in (a) are from HadCRUT3 (Brohan et al. 2006). Observations in (b) are the CMIP5 recommended forcing data.

In both CESM1(BGC) 20C experiments, the model's net $\mathrm{CO}_{2}$ tracer reproduces reasonably well the observed increase in atmospheric $\mathrm{CO}_{2}$ up to around 1940 (Fig. 2b). Recall that this $\mathrm{CO}_{2}$ tracer in the PRES experiment is purely diagnostic and does not affect $\mathrm{CO}_{2}$-related computations. The modeled $\mathrm{CO}_{2}$ diverges from the observations after that, with the model predicting higher than the observed $\mathrm{CO}_{2}$. In the 20C PRES experiment, where $\mathrm{CO}_{2}$-related computations use observed atmospheric $\mathrm{CO}_{2}$, the modeled surface atmospheric $\mathrm{CO}_{2}$ increases by 125 ppmv from 1850 to 2005, which is 31 ppmv larger than the observed increase of $94 \mathrm{ppmv}$. Drift, computed from the 1850 PRES experiment, accounts for $\sim 1.4 \mathrm{ppmv}$ of this bias. In the 20C PROG experiment, where the model is forced with fossil fuel emissions and $\mathrm{CO}_{2}$-related computations use the simulated $\mathrm{CO}_{2}$, the modeled surface atmospheric $\mathrm{CO}_{2}$ increases by $114 \mathrm{ppmv}$. Drift, in this instance computed from the 1850 PROG experiment, only accounts for $\sim 0.5 \mathrm{ppmv}$ of this increase. The reduction in the twentieth-century increase of atmospheric $\mathrm{CO}_{2}$ from the 20C PRES experiment to the 20C PROG experiment is a result of enhanced uptake by the ocean and land, reflecting the higher-thanobserved atmospheric $\mathrm{CO}_{2}$ in the 20C PROG experiment. Over the 156-yr duration of the experiments, the ocean and land take up an additional 16.5 and $6.2 \mathrm{PgC}$, respectively, in the 20C PROG experiment, compared to the 20C PRES experiment.

Consistent with the modeled $\mathrm{CO}_{2}$ being higher than the observed $\mathrm{CO}_{2}$, the net flux of $\mathrm{CO}_{2}$ into the atmosphere in the CESM1(BGC) experiments is higher than the observationally based estimates (Tables 3 and 4; Fig. 3a). Additionally, the net surface flux into the atmosphere in the 20C PRES experiment is greater than in the 20C PROG experiment. This net $\mathrm{CO}_{2}$ flux can be partitioned into components from fossil fuels, the ocean, and the land. We do that here and compare the individual components to published estimates. The fossil fuel emissions in the CESM1(BGC) experiments are consistent with the late-twentieth-century estimates of Canadell et al. (2007) and the estimate of their integral provided by Sabine et al. (2004) (Tables 3 and 4; Fig. 3b).

The late-twentieth-century decadal means of the net sea-to-air flux in the PRES experiment, which is forced with the observed atmospheric $\mathrm{CO}_{2}$, are outside the range of the Canadell et al. (2007) estimates, with the model having too little uptake (Table 3; Fig. 3c). In comparison to the Sabine et al. (2004) anthropogenic carbon inventory estimate for 1994, the model also has a low bias, where the model inventory has been computed as the integral of the air-to-sea flux plus a correction for drift in the natural carbon inventory (Table 4). A caveat with the inventory comparison is that the Sabine et al. (2004) estimate of anthropogenic carbon inventory includes carbon uptake that occurred prior to 1850 , while the model results only include uptake after 1850 . Based on Fig. 3 of Khatiwala et al. (2009), we estimate pre-1850 anthropogenic ocean uptake to be $12 \pm 3 \mathrm{Pg} \mathrm{C}$. Modeled ocean uptake is still low when this is taken into account, 
TABLE 3. Decadal means of sources and sinks of $\mathrm{CO}_{2}$ into and out of the atmosphere in 20C experiments and the estimates of Canadell et al. (2007). Explanation of the separation of land terms is given in the text. All terms have units of $\mathrm{Pg} \mathrm{Cyr}^{-1}$ and follow the positive up sign convention.

\begin{tabular}{|c|c|c|c|c|c|c|}
\hline \multirow[b]{2}{*}{ Term } & \multicolumn{3}{|c|}{ 1970-99 } & \multicolumn{3}{|c|}{ 1990-99 } \\
\hline & Canadell & PRES & PROG & Canadell & PRES & PROG \\
\hline Atmospheric accumulation & $3.1 \pm 0.04$ & 4.17 & 3.74 & $3.2 \pm 0.04$ & 4.59 & 4.18 \\
\hline Fossil fuel emission & $5.6 \pm 0.3$ & 5.43 & 5.43 & $6.5 \pm 0.3$ & 6.22 & 6.22 \\
\hline Sea-to-air flux & $-2.0 \pm 0.4$ & -1.54 & -1.87 & $-2.2 \pm 0.4$ & -1.76 & -2.19 \\
\hline Land-to-air flux & $-0.5 \pm 0.5$ & 0.28 & 0.18 & $-1.1 \pm 0.5$ & 0.13 & 0.14 \\
\hline Land-use emissions & $1.5 \pm 0.5$ & 1.42 & 1.43 & $1.6 \pm 0.5$ & 1.53 & 1.54 \\
\hline Land-to-air residual flux & $-2.0 \pm 0.7$ & -1.14 & -1.25 & $-2.7 \pm 0.7$ & -1.40 & -1.40 \\
\hline
\end{tabular}

but the bias is reduced. This low ocean uptake bias is also present in CCSM3 coupled experiments that included the carbon cycle (Thornton et al. 2009) and in oceanalone and ocean-ice experiments using CCSM3 (Wang et al. 2012) and CESM1(BGC) (Long et al. 2013). Processes that play a role in this bias in the CESM1(BGC) results are analyzed by Long et al. (2013) and include weak ventilation of intermediate depth waters from the Southern Ocean. Uptake of $\mathrm{CO}_{2}$ by the ocean in the PROG experiment is greater than in the PRES experiment because of the higher-than-observed atmospheric $\mathrm{CO}_{2}$ in the PROG experiment. This increased uptake yields fluxes and inventories that are within the Canadell et al. (2007) and Sabine et al. (2004) ranges. This agreement should be viewed with caution though, because it is the result of compensating biases, weak uptake efficiency paired with stronger atmospheric $\mathrm{CO}_{2}$ forcing.

Without the PRES experiment, which is the situation for most CMIP5 ESM models, we would only have the PROG experiment to compare to independent ocean uptake estimates. Such a comparison is not straightforward because of the bias in the atmospheric $\mathrm{CO}_{2}$ in the PROG experiment. One approach to attempt to account for this forcing mismatch is to compare integrated ocean uptake in the PROG experiment with the observational anthropogenic inventory at the time in the experiment where the over-ocean average of the modeled atmospheric $\mathrm{CO}_{2}$ reaches the observed 1994 value of $359 \mathrm{ppmv}$. The model achieves this value in model year 1986, 8 years too early, and the driftcorrected integrated uptake at the end of 1986 is $85 \mathrm{PgC}$. This value is outside the Sabine et al. (2004) range, as expected, but is also lower than the anthropogenic inventory in the PRES experiment at 1994, making us conclude that the approach is not entirely satisfactory. We attribute the discrepancy to unresolved mismatches between the adjusted PROG anthropogenic inventory and the observationally based estimate, such as the time history of the atmospheric $\mathrm{CO}_{2}$. This discrepancy highlights the difficulty in rigorously comparing uptake from the 20C PROG experiment to observationally based estimates.

The net land-to-air flux in both PRES and PROG experiments is outside the range of the Canadell et al. (2007) estimates (Table 3; Fig. 3d). With few exceptions, the CESM1(BGC) values are within the CCSM4 envelope. Because of model and forcing similarities, this is not surprising for the 20C PRES experiment. For the 20C PROG experiment, this agreement indicates that the model's response to the anomalously high $\mathrm{CO}_{2}$ in this experiment is smaller than variability in the model's carbon system.

To highlight separate processes that contribute to this net land-to-air flux, we have separated it into two components: land-use emissions and land-to-air residual flux. The term land-use emissions denotes the release of $\mathrm{CO}_{2}$ to the atmosphere that occurs directly from landuse change and wood harvesting. It is the sum of the land-cover conversion flux and product pool release flux.

TABLE 4. Integrated sources and sinks of $\mathrm{CO}_{2}$ into and out of the atmosphere in $20 \mathrm{C}$ experiments. Integrals for the model are adjusted to remove drift, using the inventory drifts reported in Table 2. All terms have units of $\mathrm{PgC}$ and follow the positive up sign convention.

\begin{tabular}{lrrrr}
\hline \hline & & \multicolumn{3}{c}{$1850-1994$} \\
\cline { 3 - 5 } \multicolumn{1}{c}{ Term } & PI-1994 & \multicolumn{1}{c}{ Est. } & PRES & PROG \\
\hline Atmospheric & & $157 \pm 4^{\mathrm{a}}$ & 210 & 192 \\
$\quad$ accumulation & & & & \\
Fossil fuel integral & $244 \pm 20^{\mathrm{b}}$ & $244 \pm 20^{\mathrm{b}}$ & 240 & 240 \\
Sea-to-air integral & $-118 \pm 19^{\mathrm{c}}$ & $-106 \pm 19^{\mathrm{d}}$ & -90 & -102 \\
Land-to-air integral & & $19 \pm 28^{\mathrm{e}}$ & 59 & 54 \\
\hline
\end{tabular}

${ }^{a}$ Computed from $\mathrm{CO}_{2}$ difference from end of 1994 (359 ppmv) and 1850 reference value $(284.7 \mathrm{ppmv})$. Converted to mass using a conversion factor of $2.11 \mathrm{Pg} \mathrm{Cppmv}^{-1}$.

${ }^{\mathrm{b}}$ Value is from Sabine et al. (2004) for 1800-1994. We are neglecting any pre-1850 correction.

${ }^{\mathrm{c}}$ Value is from Sabine et al. (2004) and includes pre-1850 uptake.

${ }^{\mathrm{d}}$ Value is from Sabine et al. (2004), with a pre-1850 adjustment estimated from Khatiwala et al. (2009).

${ }^{\mathrm{e}}$ Computed as a residual of other 1850-1994 terms. 

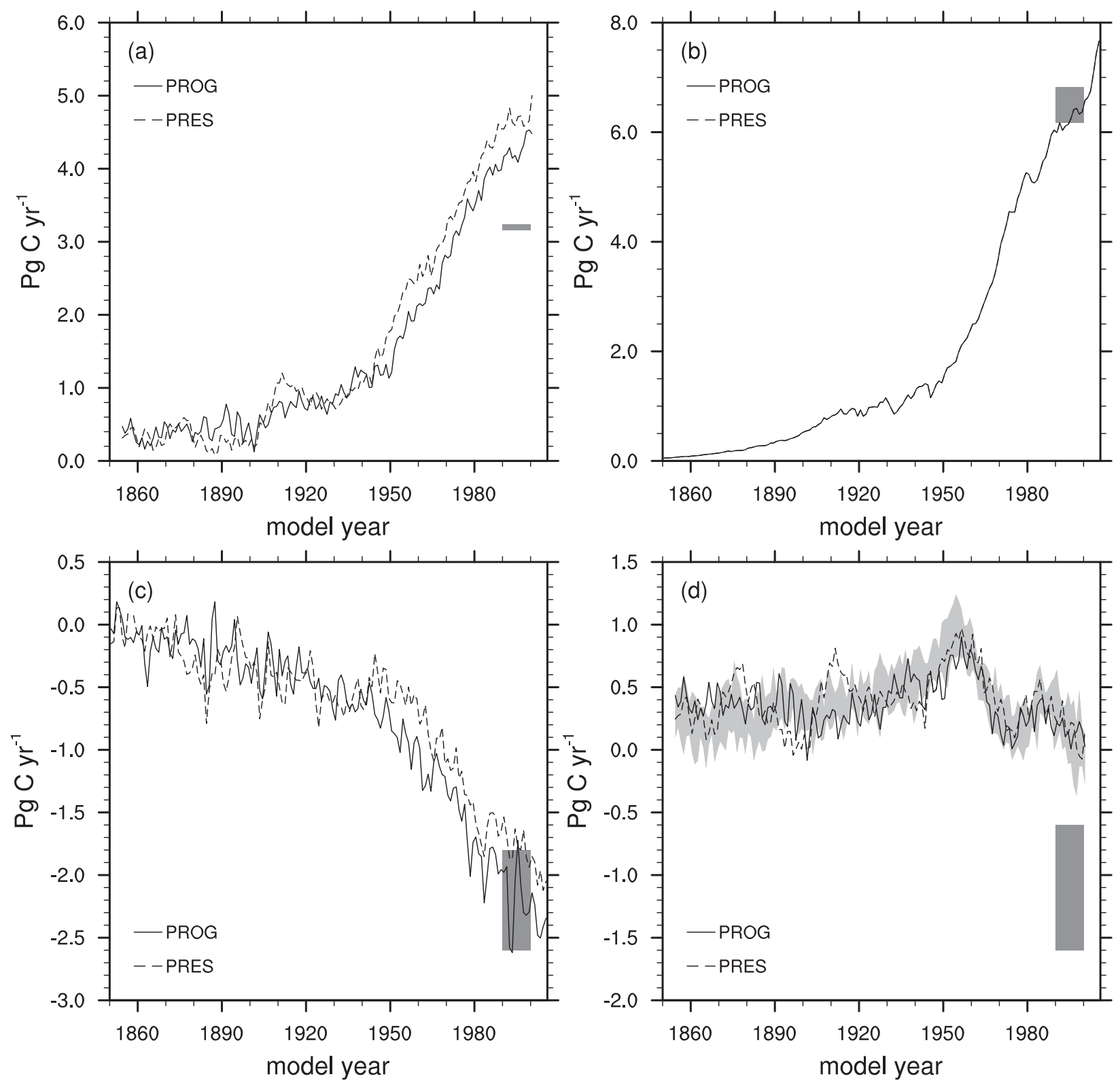

FIG. 3. Time series of $20 \mathrm{C} \mathrm{(a)} \mathrm{net,} \mathrm{(b)} \mathrm{fossil} \mathrm{fuel,} \mathrm{(c)} \mathrm{ocean,} \mathrm{and} \mathrm{(d)} \mathrm{land} \mathrm{CO}_{2}$ surface flux into the atmosphere. Annual mean values, filtered with a 10-point boxcar filter to remove interannual variability, are depicted in (a) and (d). Annual mean values are depicted in (b) and (c). Dark shading denotes estimates for 1990-99 from Canadell et al. (2007). Light shading in (d) denotes maximum and minimum filtered fluxes over seven CCSM4 20C ensemble members. The sign convention of the fluxes in each panel is positive up.

The land-to-air residual flux is the difference of the net land-to-air flux and land-use emissions. We use this particular separation of the land-to-air flux because it can be cleanly extracted from model output, and we can straightforwardly compare it to estimates from Canadell et al. (2007). Land-use emissions in CESM1(BGC) are nearly identical to the emissions in the CCSM4 ensemble members (Fig. 4a). The reason for this is that they depend mainly on a prescribed forcing, the historical change in the fractional area of PFTs. The late-twentiethcentury decadal means of this emission are within the Canadell et al. (2007) ranges (Table 3; Fig. 4a). Houghton (2003) estimates the integrated land-use emissions over $1850-2000$ to be $156 \mathrm{Pg} \mathrm{C}$, while the integral from both CESM1(BGC) experiments is 113 and $114 \mathrm{Pg} \mathrm{C}$ for the PROG and PRES experiments, respectively. Houghton (2003) does not provide an estimate of uncertainty for the integrated flux, so it is not clear how significant this 
mismatch is. With few exceptions, the land-to-air residual flux in CESM1(BGC) is within the CCSM4 envelope (Fig. 4b). For the 20C PROG experiment, this again indicates that the model's response to the anomalously high $\mathrm{CO}_{2}$ in this experiment is smaller than variability in the model's carbon system. The mean flux over 1970-99 in both 20C experiments is outside the Canadell et al. (2007) range, with the PROG experiment being closer (Table 3; Fig. 4). However, it is more appropriate to compare the PRES value to the Canadell et al. (2007) estimate, because atmospheric $\mathrm{CO}_{2}$ in the PROG experiment exceeds the observed atmospheric $\mathrm{CO}_{2}$, leading to an overestimate of the $\mathrm{CO}_{2}$ fertilization-induced sink. The disagreement between the model and the Canadell et al. (2007) range is greater over 1990-99. However, because of the large variability of the flux, the smaller time span increases the uncertainty in comparing a free-running model to contemporary estimates. It is not clear which processes in the model are the primary factors leading to this low uptake bias, and an analysis of the bias is beyond the scope of this manuscript. That said, previous studies (Thornton et al. 2007; Bonan and Levis 2010) have demonstrated that nitrogen limitation reduces uptake from the $\mathrm{CO}_{2}$ fertilization effect. Additionally, comparisons of CLM-CN to Coupled Climate Carbon Cycle Model Intercomparison Project (C4MIP) models (Thornton et al. 2009) and CLM4CN to CMIP5 models (Arora et al. 2013) demonstrate that CLM, with its nitrogen cycle enabled, has a smaller $\mathrm{CO}_{2}$ fertilization effect than models that do not include the coupling of terrestrial carbon and nitrogen cycles. This limiting process, combined with too-rapid turnover of soil organic matter (Todd-Brown et al. 2013), are likely drivers of the low uptake bias. Biases in the model's climate (e.g., temperature, precipitation, and sunlight) may also be contributing factors. We do point out that development versions of CLM have substantially greater uptake of anthropogenic $\mathrm{CO}_{2}$ in offline simulations (Koven et al. 2013).

In summary, the high atmospheric $\mathrm{CO}_{2}$ concentrations in the CESM1(BGC) 20C experiments are the result of biases in the sea- and land-to-air $\mathrm{CO}_{2}$ fluxes (Fig. 2b). Based on comparison with published estimates (Canadell et al. 2007) of these fluxes over the late-twentieth century, we conclude that bias in the land-to-air fluxes accounts for the majority of the flux bias. Further decomposition of the land-to-air flux indicates that processes regulating the net biological uptake of carbon by the land are the likely cause of the bias in the land-to-air flux.

\section{d. Carbon reservoir budgets}

In this subsection, we summarize carbon budgets in the ocean and land reservoirs, presenting results for the
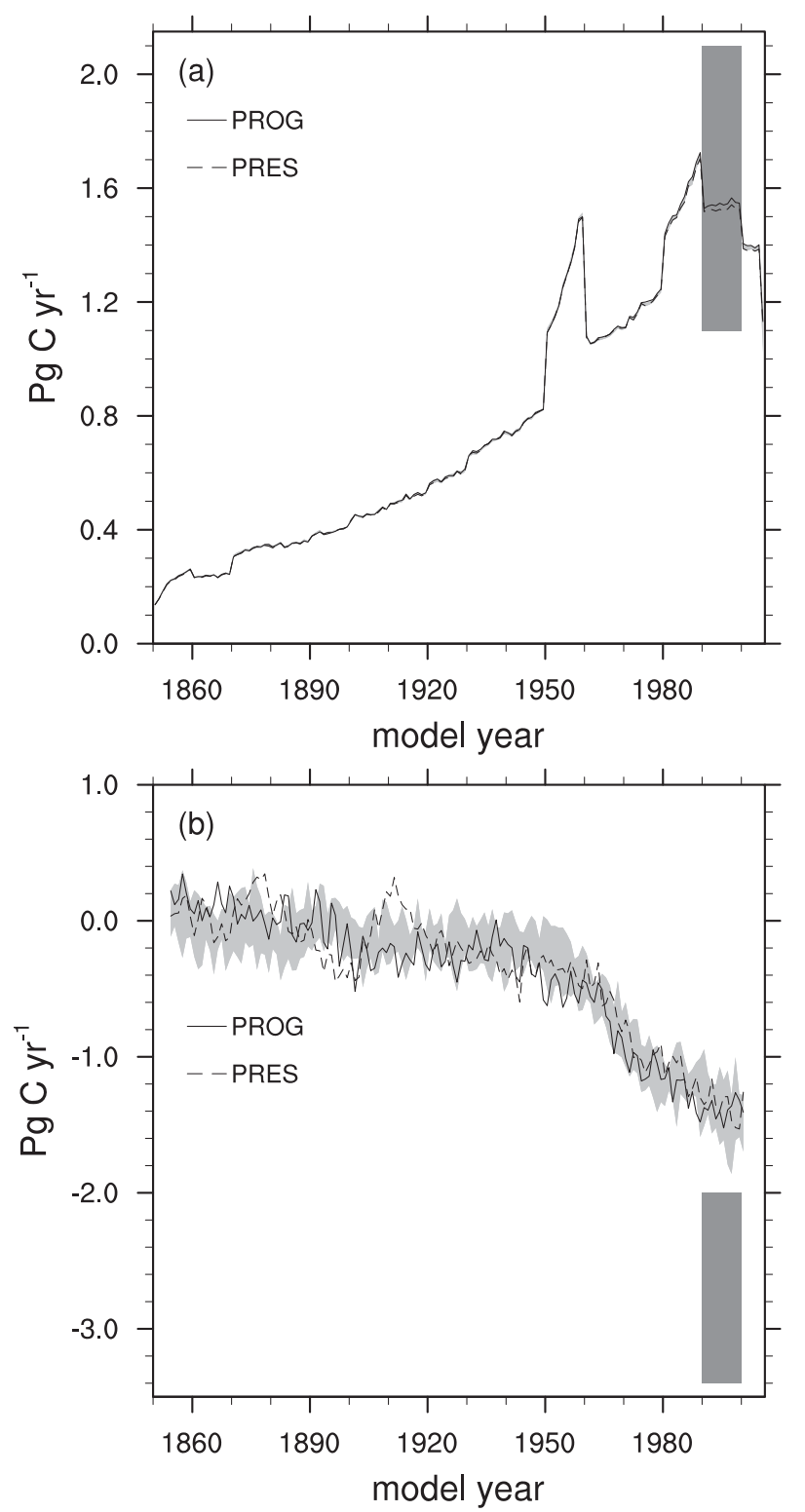

FIG. 4. Time series of 20C (a) land-use emissions and (b) land-toair residual $\mathrm{CO}_{2}$ surface flux into the atmosphere. Annual mean values are depicted in (a). Annual mean values, filtered with a 10-point boxcar filter to remove interannual variability, are depicted in (b). Dark shading denotes estimates from Canadell et al. (2007). Light shading denotes maximum and minimum filtered fluxes over seven CCSM4 20C ensemble members. The sign convention of the fluxes in each panel is positive up.

1850 and 20C PRES experiments. Except as noted below, results for the PROG experiments are very similar.

For the ocean reservoir, we present terms related to the exchange of carbon, in its organic and inorganic forms, in and out of the top $100 \mathrm{~m}$, as well as terms for the formation of organic matter within the top $100 \mathrm{~m}$ (Table 5). The only terms with considerably different 
TABLE 5. Key terms in the ocean carbon budget over the top $100 \mathrm{~m}$. Terms for the 1850 and 20C PRES experiments are from annual means averaged over years $121-320$ and 1981-2005, respectively. All terms have units of $\mathrm{PgC}^{-1}$, and fluxes follow the positive down sign convention. Dissolved organic carbon (DOC) is carbon content in dead suspended organic matter. Sinking particulate organic carbon (sPOC) is carbon content in dead sinking organic matter and DIC is dissolved inorganic carbon.

\begin{tabular}{lccr}
\hline \multicolumn{1}{c}{ Term } & 1850 PRES & 20C PRES & Difference \\
\hline Air-to-sea $\mathrm{CO}_{2}$ flux & -0.024 & 1.774 & 1.798 \\
Primary production & 55.55 & 55.73 & 0.173 \\
DOC production & 23.56 & 23.67 & 0.114 \\
sPOC production & 11.47 & 11.39 & -0.087 \\
DOC flux, 100 m & 2.82 & 2.73 & -0.091 \\
sPOC flux, 100m & 8.08 & 8.01 & -0.075 \\
DIC flux, 100 m & -12.58 & -10.83 & 1.744 \\
\hline
\end{tabular}

values in the PROG experiments (not shown) are the air-to-sea $\mathrm{CO}_{2}$ flux and 100-m dissolved inorganic carbon (DIC) flux terms, and these differences only occur in the $20 \mathrm{C}$ experiments. The differences are due to the terms' strong dependence on atmospheric $\mathrm{CO}_{2}$, which differs in the 20C PROG experiment from its prescribed values in the 20C PRES experiment. The near-zero value for the air-to-sea $\mathrm{CO}_{2}$ flux for the 1850 experiment, $-0.024 \mathrm{PgC} \mathrm{yr}^{-1}$, reflects the small magnitude of drift in the ocean's carbon inventory (Table 2). The change in this term in the $20 \mathrm{C}$ experiment reflects uptake of anthropogenic carbon by the ocean, which again is low compared to the Canadell et al. (2007) estimate. The only subsurface carbon budget term that changes appreciably in the $20 \mathrm{C}$ experiment from the 1850 experiment is the reduction of net upward physical flux of carbon into the top $100 \mathrm{~m}$. Photosynthesis fixes 55.6 $\mathrm{Pg} \mathrm{Cyr}^{-1}$ into living organisms in the upper $100 \mathrm{~m}$, which is within the broad range, $36-68 \mathrm{Pg} \mathrm{Cyr}^{-1}$, of the satellite-based estimates analyzed by Carr et al. (2006). The processes of mortality, grazing, and aggregation produce 23.6 and 11.5 $\mathrm{Pg} \mathrm{Cyr}^{-1}$ of dead suspended and sinking organic matter, respectively. The majority of the remaining $20.5 \mathrm{Pg} \mathrm{Cyr}^{-1}$ of fixed carbon is routed directly to DIC in the top $100 \mathrm{~m}$. Approximately $31 \%\left(10.9 \mathrm{Pg} \mathrm{C} \mathrm{yr}^{-1}\right)$ of the produced dead organic matter is exported below
$100 \mathrm{~m}$, while the remainder is remineralized in the upper $100 \mathrm{~m}$. Calcifiers in the model account for an additional 1.1 $\mathrm{Pg} \mathrm{C} \mathrm{yr}^{-1}$ of carbon fixation into $\mathrm{CaCO}_{3}$ and $0.8 \mathrm{Pg} \mathrm{Cyr}^{-1}$ of sinking $\mathrm{CaCO}_{3}$ export at $100 \mathrm{~m}$. The downward organic carbon flux from sinking particles and transport of suspended organic matter, living and dead, is balanced by the $12.6 \mathrm{Pg} \mathrm{Cyr}^{-1}$ of net upward transport of DIC. Further details on the dynamics of the ocean ecosystem and carbon cycle are given by Moore et al. (2013) and Long et al. (2013).

For the land reservoir, we present a breakdown of the carbon inventory into vegetation, coarse woody debris, litter, soil, and wood product pools (Table 6). The results for the PROG experiments, not shown, are all very similar to the PRES experiments.

The $533 \mathrm{Pg} \mathrm{C}$ for global vegetation carbon is comparable to that found in other global carbon-nitrogen biogeochemical models for the late-twentieth century. Zaehle et al. (2010), using a version of the Organizing Carbon and Hydrology in Dynamic Ecosystems (ORCHIDEE) model (Krinner et al. 2005) designed to account for terrestrial $\mathrm{N}$ feedbacks $(\mathrm{O}-\mathrm{CN})$, simulated $537 \mathrm{Pg} \mathrm{C}$ in vegetation, compared with observationally based estimates of 560-652 Pg C. Wang et al. (2010), using the CASACNP model, which is based on the Carnegie-Ames-Stanford Approach (CASA) (Randerson et al. 1997, hereafter R97) and CASA' (Fung et al. 2005) models, simulated $520 \mathrm{Pg} \mathrm{C}$ in vegetation. The $501 \mathrm{Pg} \mathrm{C}$ global soil carbon is low compared with those of O-CN (1289 Pg C) and CASACNP (2124 Pg C). Observed global soil carbon estimates vary considerably, especially with respect to soil depth. Todd-Brown et al. (2013) report an estimate of $1260 \mathrm{Pg} \mathrm{C}$ for a depth range of up to $1 \mathrm{~m}$ (with a $95 \%$ confidence interval of $890-1660 \mathrm{Pg} \mathrm{C}$ ) from the Harmonized World Soil Database. Zaehle et al. (2010) cited values ranging from $700-3000 \mathrm{Pg} \mathrm{C}$, and Wang et al. (2010) cited values ranging from 1500 $2300 \mathrm{PgC}$. The low soil carbon relative to vegetation carbon in our coupled experiments with CLM4CN is seen also in uncoupled experiments for the late-twentieth century reported by Thornton et al. (2007) using an earlier version of the model $(698 \mathrm{PgC}$ in vegetation and

TABLE 6. Global carbon inventory in land pools. Terms for the 1850 and 20C PRES experiments are from annual means averaged over years 121-320 and 1981-2005, respectively. All inventories have units Pg C.

\begin{tabular}{|c|c|c|c|c|}
\hline Field name & Carbon pool description & 1850 PRES & 20C PRES & Difference \\
\hline TOTVEGC & Total vegetation & 599.50 & 533.22 & -66.28 \\
\hline CWDC & Coarse woody debris & 69.55 & 61.60 & -7.94 \\
\hline TOTLITC & Total litter & 10.65 & 11.59 & 0.94 \\
\hline TOTSOMC & Total soil organic matter & 492.12 & 501.03 & 8.91 \\
\hline TOTPRODC & Total wood product & 0.00 & 8.00 & 8.00 \\
\hline TOTECOSYSC & Total ecosystem & 1171.82 & 1115.44 & -56.38 \\
\hline
\end{tabular}


TABLE 7. Key terms in the land nitrogen budget. Terms for the 1850 and 20C PRES experiments are from annual means averaged over years 121-320 and 1981-2005, respectively. All terms have units $\mathrm{Tg} \mathrm{N} \mathrm{yr}^{-1}$.

\begin{tabular}{|c|c|c|c|c|}
\hline Field name & Nitrogen flux description & 1850 PRES & 20C PRES & Difference \\
\hline NDEP_TO_SMINN & Deposition & 19.35 & 63.11 & 43.76 \\
\hline NFIX_TO_SMINN & Fixation & 101.86 & 107.60 & 5.74 \\
\hline DENIT & Denitrification & 96.80 & 114.67 & 17.87 \\
\hline SMINN_LEACHED & Leached & 0.01 & 0.02 & 0.00 \\
\hline GROSS_NMIN & Gross mineralization & 1908.48 & 2018.63 & 110.14 \\
\hline ACTUAL_IMMOB & Actual immobilization & 1277.58 & 1325.76 & 48.19 \\
\hline NET_NMIN & Net mineralization & 630.91 & 692.87 & 61.96 \\
\hline SMINNN_TO_PLANT & Plant uptake of soil mineral $\mathrm{N}$ & 654.74 & 747.36 & 92.62 \\
\hline
\end{tabular}

$344 \mathrm{PgC}$ in soil) and Bonan and Levis (2010) using CLM4CN (766 Pg C in vegetation and $750 \mathrm{Pg} \mathrm{C}$ in soil). Development versions of CLM, which include a more sophisticated treatment of soil, have substantially more soil carbon globally in offline simulations (Koven et al. 2013).

For completeness, we also present key terms from the land model's nitrogen budget (Table 7), comparing the 20C PRES results to estimates from the literature, including results from other models. Results for the PROG experiments, not shown, are all similar to the results for the PRES experiments. Nitrogen deposition onto land in CESM1(BGC) is comparable to the $64 \mathrm{Tg} \mathrm{N} \mathrm{yr}^{-1}$ value for the early 1990s reported by Galloway et al. (2004). Zaehle et al. (2010) used $52 \mathrm{Tg} \mathrm{Nyr}^{-1}$ in O-CN, and Wang et al. (2010) used $69 \mathrm{Tg} \mathrm{Nyr}^{-1}$ in CASACNP. Biological nitrogen fixation is another source of nitrogen in the system, and our result $\left(107.6 \mathrm{Tg} \mathrm{N} \mathrm{yr}^{-1}\right)$ is comparable with estimates of $107 \mathrm{Tg} \mathrm{N} \mathrm{yr}^{-1}$ for natural systems (Galloway et al. 2004, with an additional $32 \mathrm{Tg} \mathrm{N} \mathrm{yr}^{-1}$ for cultivation) and $108 \mathrm{Tg} \mathrm{N} \mathrm{yr}^{-1}$ in O-CN, but less than the $142 \mathrm{Tg} \mathrm{N} \mathrm{yr}^{-1}$ in CASACNP. The O-CN and CASACNP models also include $\mathrm{N}$ input from fertilizer, estimated to be about $100 \mathrm{Tg} \mathrm{N} \mathrm{yr}^{-1}$ (Galloway et al. 2004), which is not included in our experiments.

The fate of this nitrogen input is much different in CLM4CN compared with O-CN and CASACNP. Some of these differences reflect inconsistent $\mathrm{N}$ inputs (e.g., lack of fertilizer in CLM4CN) but still illustrate fundamental disparity in the simulated $\mathrm{N}$ cycles. For example, nitrogen export in leaching is virtually nonexistent. O-CN estimates global $\mathrm{N}$ leaching to be $86 \mathrm{Tg} \mathrm{N} \mathrm{yr}^{-1}$, much of which $\left(57 \mathrm{Tg} \mathrm{Nyr}^{-1}\right)$ is related to fertilizer application (Zaehle et al. 2010), and the CASACNP estimate is $60 \mathrm{Tg} \mathrm{N} \mathrm{yr}^{-1}$ (Wang et al. 2010). Total $\mathrm{N}$ emission to the atmosphere is $115 \mathrm{Tg} \mathrm{Nyr}^{-1}$, compared with $98 \mathrm{Tg} \mathrm{N} \mathrm{yr}^{-1}$ (O-CN) and $240 \mathrm{Tg} \mathrm{N} \mathrm{yr}^{-1}$ (CASACNP).

CLM4CN has a less intensive internal $\mathrm{N}$ cycle than $\mathrm{O}-\mathrm{CN}$ and CASACNP, which may reflect, in part, the lower net primary production (NPP) $\left(45 \mathrm{Pg} \mathrm{Cyr}^{-1}\right)$ compared with $\mathrm{O}-\mathrm{CN}\left(58 \mathrm{PgC}^{-1}\right)$ and CASACNP $\left(51 \mathrm{Pg} \mathrm{Cyr}^{-1}\right)$. Net nitrogen mineralization is approximately one-third less than that simulated by $\mathrm{O}-\mathrm{CN}$ $\left(1028 \mathrm{Tg} \mathrm{N} \mathrm{yr}^{-1}\right)$ and CASACNP (1100 $\mathrm{Tg} \mathrm{N} \mathrm{yr}^{-1}$ ). Plant uptake is also one-third smaller than $\mathrm{O}-\mathrm{CN}$ (1127 $\mathrm{Tg} \mathrm{N} \mathrm{yr}^{-1}$ ) and CASACNP (1100 $\mathrm{Tg} \mathrm{N} \mathrm{yr}^{-1}$ ).

\section{e. Interannual variability in the carbon cycle}

In this subsection, we summarize interannual variability in atmospheric $\mathrm{CO}_{2}$ and its surface fluxes. In the following, interannual variance for various quantities is constructed from model monthly means by subtracting the model's mean monthly climatology, detrending (by subtracting the least squares linear fit), and then computing the variance.

The highest variability in surface atmospheric $\mathrm{CO}_{2}$ occurs over land, where variability is primarily within subdecadal time scales (Fig. 5). Away from the geographic vicinity of land, variance of surface atmospheric $\mathrm{CO}_{2}$ is primarily on decadal-and-longer time scales. This variability lacks spatial structure, because the atmosphere mixes passive tracers efficiently on these time scales (Holzer 1999). Consequently, in these regions, decadal atmospheric $\mathrm{CO}_{2}$ tracks the decadal global mean. Indeed, in regions where more than $50 \%$ of the interannual variance is on decadal-and-longer time scales, $96 \%$ of this variance is accounted for by the decadal time series of globally averaged surface atmospheric $\mathrm{CO}_{2}$.

Interannual variability of atmospheric $\mathrm{CO}_{2}$ is directly forced by variability of the $\mathrm{CO}_{2}$ fluxes provided by the surface components (Fig. 6). The spatial patterns of variability of the land-to-air flux closely follow the patterns of $\mathrm{CO}_{2}$ variability. This is consistent with $\mathrm{CO}_{2}$ variability being primarily driven by flux variability, instead of transport. These flux variations are, in turn, driven by variations in climatic forcings, such as precipitation and air temperature. As is the case with $\mathrm{CO}_{2}$ variability over land, the variability of the land-to-air $\mathrm{CO}_{2}$ fluxes is primarily in subdecadal time scales.

Variability in sea-to-air $\mathrm{CO}_{2}$ fluxes is largest in the North Atlantic, the Antarctic Circumpolar Current, the 
(a)

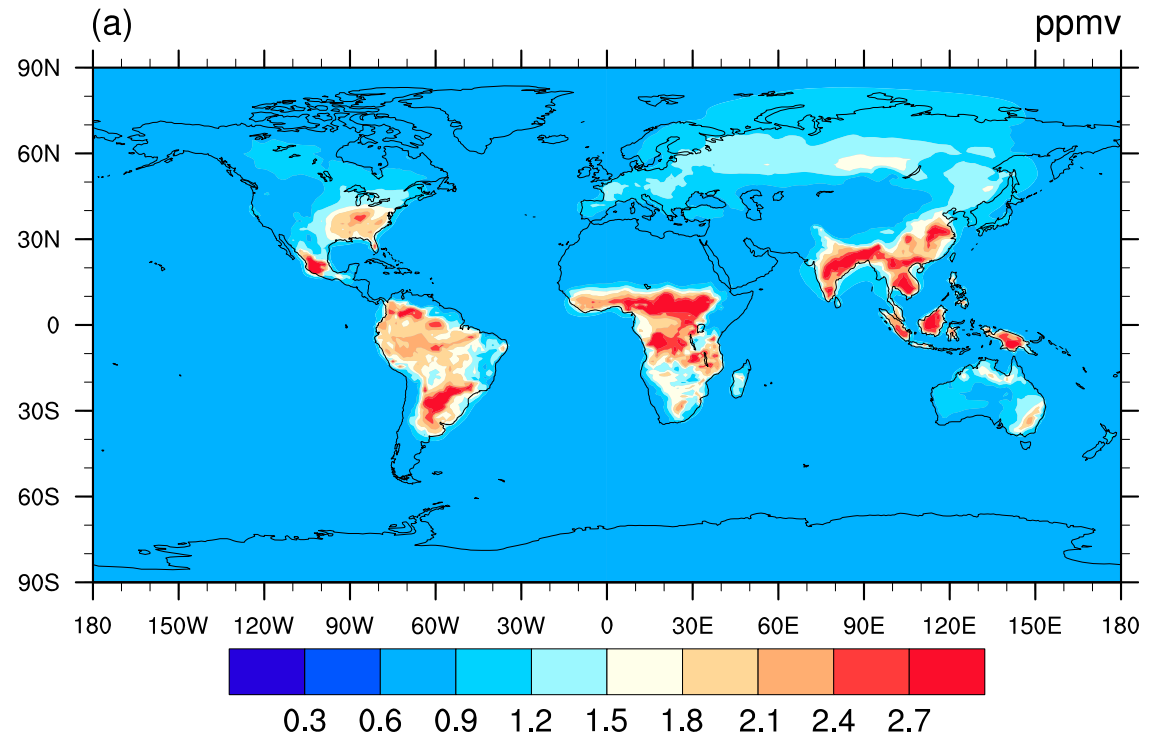

(b)

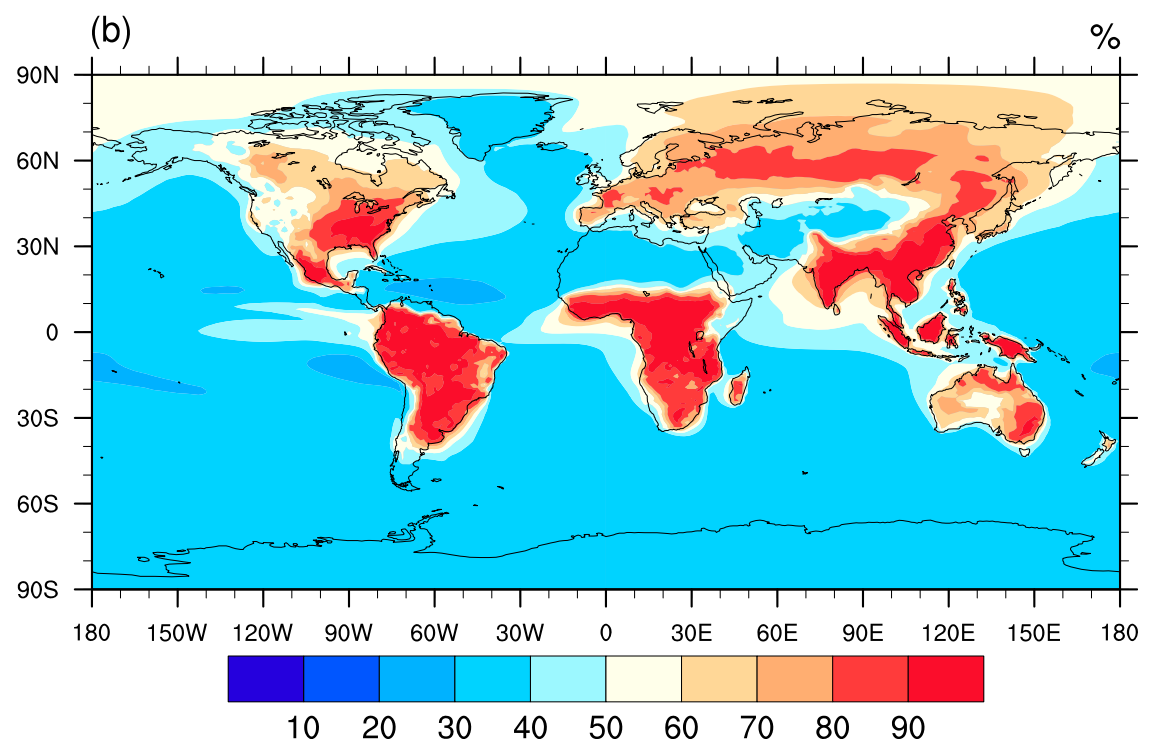

FIG. 5. (a) Interannual RMS of surface atmospheric $\mathrm{CO}_{2}$ and (b) percentage of variance in subdecadal time scales. Results are from the 1850 PROG experiment (years 1-1000).

eastern tropical Pacific and the northwest Pacific. The spatial patterns are similar to those described by Doney et al. (2009), who describe the mechanisms governing interannual sea-to-air $\mathrm{CO}_{2}$ flux variability in ocean-alone experiments that were performed using a previous version of the ocean GCM and ocean biogeochemical model that is used in CESM1(BGC) (Fig. 6). Long et al. (2013) examine the relationship between variability in sea-toair $\mathrm{CO}_{2}$ fluxes and modes of climate variability in CESM1(BGC).

The power spectra of the detrended monthly anomalies of globally averaged surface atmospheric $\mathrm{CO}_{2}$ reveal that the largest amount of variability occurs on multidecadal-to-centennial time scales and that there is a peak in variance in the ENSO-related 3-6-yr band (Fig. 7). The magnitude of the low-frequency variability is consistent with a first-order Markov process that has the same lag-one autocorrelation as the $\mathrm{CO}_{2}$ time series, which is 0.994 and 0.996 for the PROG and PRES experiments, respectively. This highlights that while there is multidecadal variability evident in the global $\mathrm{CO}_{2}$ time series (Fig. 1), it is not necessarily associated with processes that occur on multidecadal time scales; it is consistent with a stochastic process.

The power spectra of the detrended monthly anomalies of the globally integrated land- and sea-to-air fluxes 


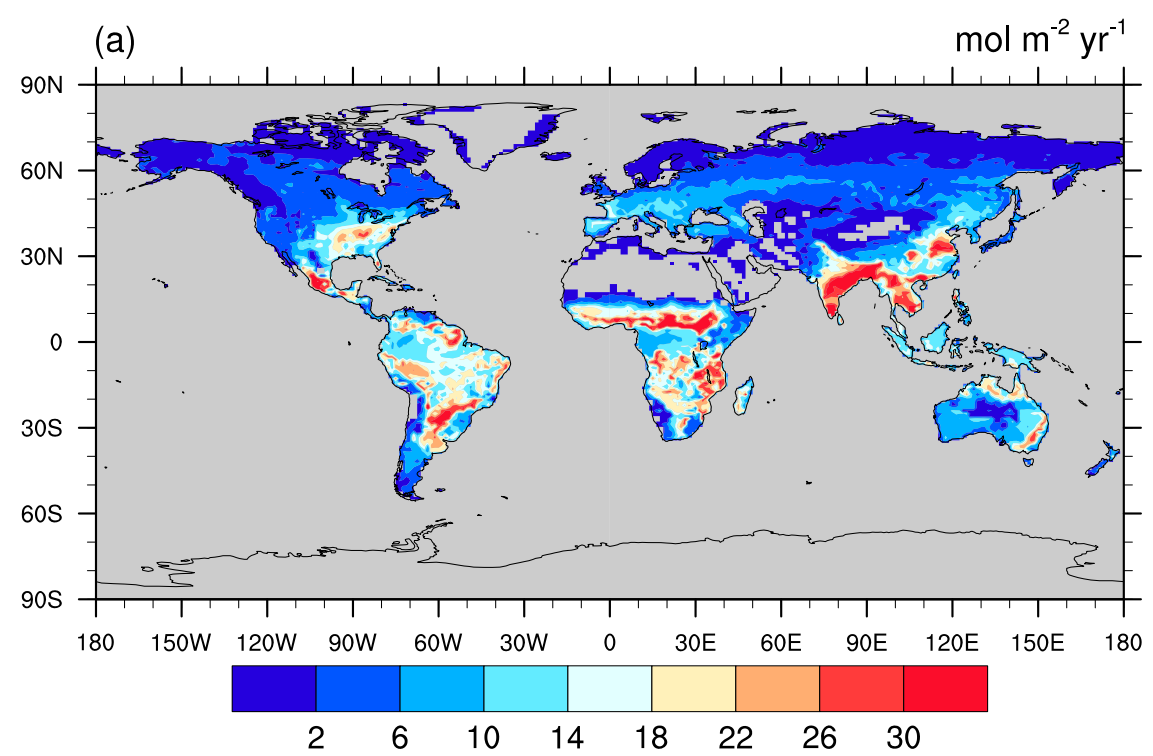

(b)

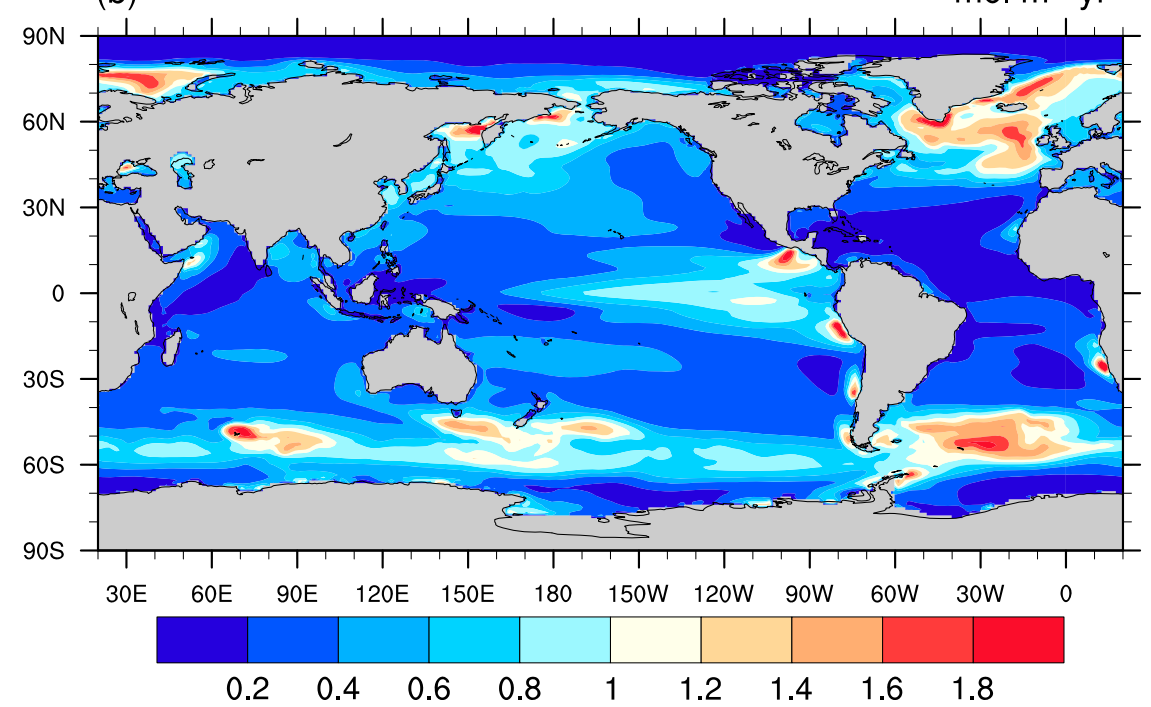

FIG. 6. Interannual RMS of (a) land-to-air and (b) sea-to-air $\mathrm{CO}_{2}$ flux. Shading indicates that the fluxes are identically zero. Results are from the 1850 PROG experiment (years 1-1000).

also show a peak in the ENSO-related 3-6-yr band (Fig. 8). These peaks exceed the $95 \%$ confidence interval of the spectrum of the corresponding first-order Markov processes, indicating statistical significance. Variance in the land-to-air fluxes is larger than variance in the sea-toair fluxes, consistent with inversion studies of latetwentieth-century $\mathrm{CO}_{2}$ fluxes (Bousquet et al. 2000).

For the land-to-air fluxes, there is slightly less variance in the PROG experiment than in the PRES experiment. This is consistent with the slightly smaller SST variability in the Niño 3.4 region in the PROG experiment that we point out below.
For the sea-to-air fluxes, the peak in variance in the PROG experiment is twice as large as the peak in variance in the PRES experiment, despite the smaller SST variability in the Niño 3.4 region in the PROG experiment. The explanation for this difference is that the prognostic $\mathrm{CO}_{2}$ in the PROG experiment induces an indirect coupling between the sea-to-air fluxes and the land-to-air fluxes. We elaborate on this by considering lagged correlation coefficients between global subdecadal time series of surface atmospheric $\mathrm{CO}_{2}$, land-toair, and sea-to-air fluxes (Fig. 9). On these time scales, variations in land-to-air fluxes lead variations in surface 

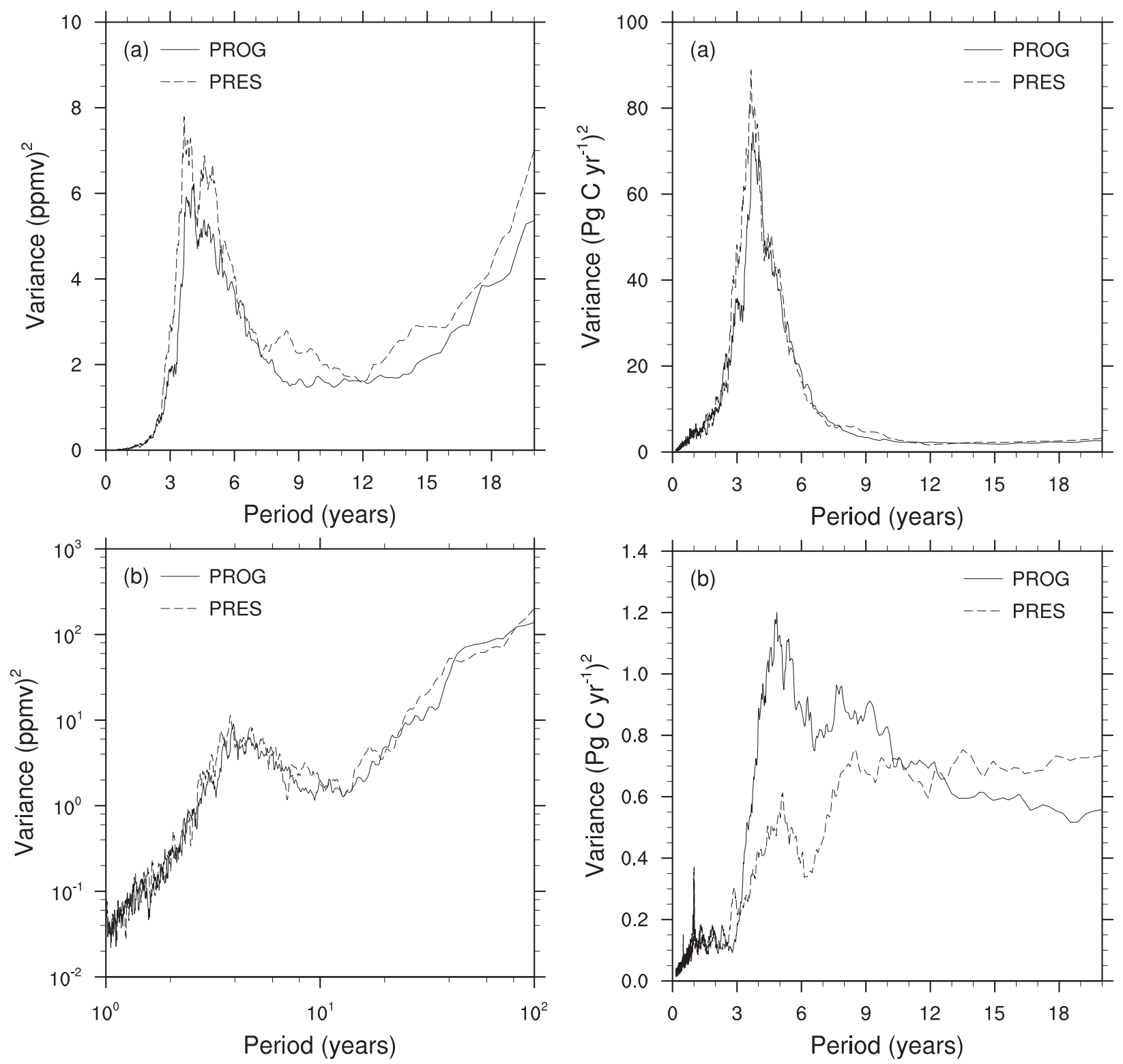

FIG. 7. (a) Power spectra of detrended monthly anomalies of globally averaged surface atmospheric $\mathrm{CO}_{2}$. (b) The same power spectra as (a) in a log-log plot with larger axis ranges to highlight the behavior of the spectra at low frequencies. The periodogram in (b) is smoothed less in order to maintain spectral features at low frequencies. Results are from the 1850 experiments (years 1-1000).

atmospheric $\mathrm{CO}_{2}$ (Fig. 9a). The relationship is essentially identical in the PROG and PRES experiments, indicating that the $\mathrm{CO}_{2}$ feedback in the PROG experiment does not change the dynamics of this relationship. In the PROG experiment, variations in surface atmospheric $\mathrm{CO}_{2}$ are concurrent with opposing variations in sea-to-air fluxes (Fig. 9b). The relationship is weaker in the PRES experiment, indicating that the $\mathrm{CO}_{2}$ feedback

FIG. 8. Power spectra of detrended monthly anomalies of globally averaged (a) land-to-air and (b) sea-to-air $\mathrm{CO}_{2}$ flux. Results are from the 1850 experiments (years 1-1000).

in the PROG experiment enhances the relationship. There is a weak negative relationship between the landand sea-to-air $\mathrm{CO}_{2}$ fluxes in the PRES experiment and a stronger negative lagged relationship in the PROG experiment (Fig. 9c). The relationship in the PRES experiment occurs because the climate variability (e.g., ENSO) that drives variability in the fluxes from the different components, through different forcing mechanism, induces a noncausal correlation in the flux components. The negative correlation is enhanced in a lagged manner when the PROG $\mathrm{CO}_{2}$ feedback is enabled. That is, 

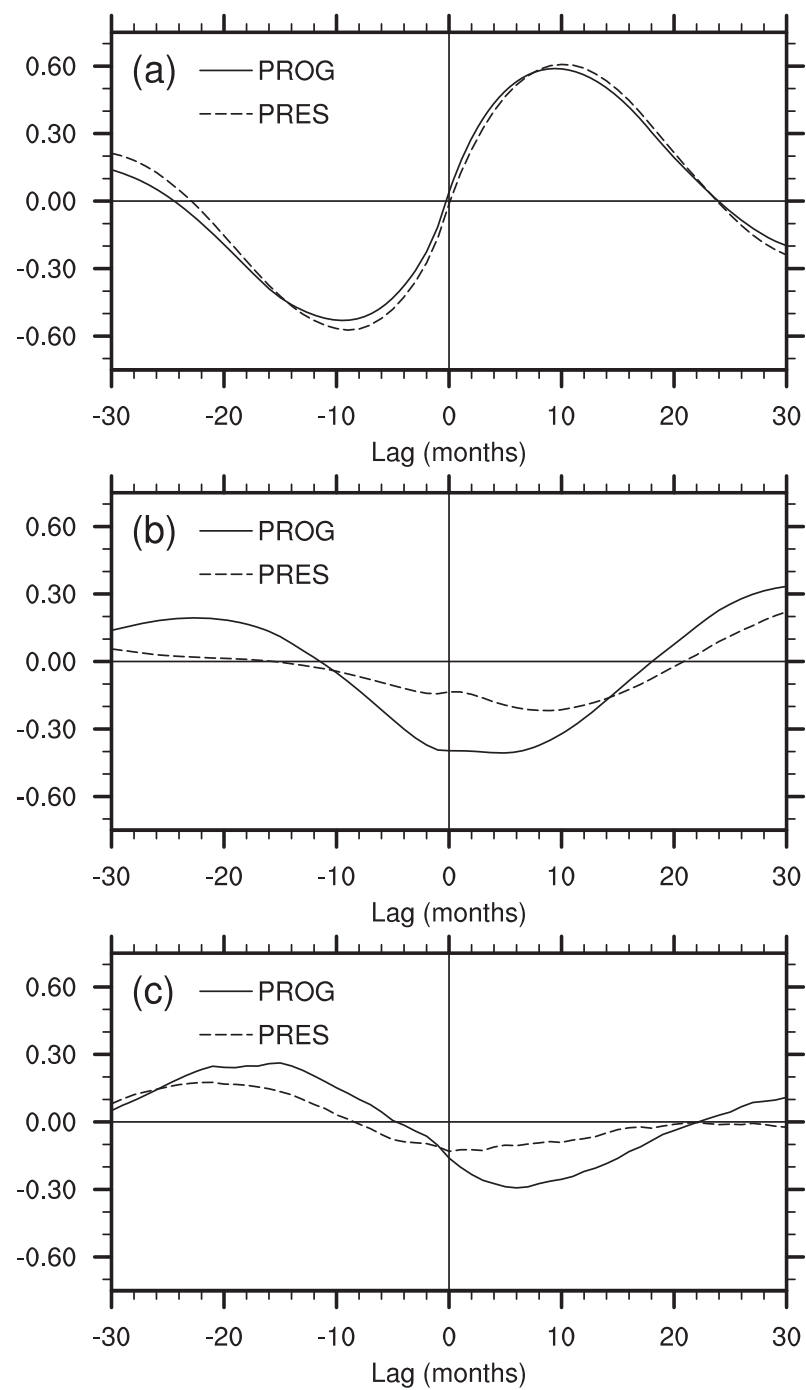

FIG. 9. Lagged correlation coefficient between subdecadal interannual global mean time series. The correlations are for (a) land-to-air $\mathrm{CO}_{2}$ flux vs surface atmospheric $\mathrm{CO}_{2}$, (b) sea-to-air $\mathrm{CO}_{2}$ flux vs surface atmospheric $\mathrm{CO}_{2}$, and (c) land-to-air $\mathrm{CO}_{2}$ flux vs sea-to-air $\mathrm{CO}_{2}$ flux. Positive lags correspond to first variable listed leading. Results are from the 1850 experiments (years $1-1000)$.

physical variability drives land-to-air flux variability, which in turn drives lagged atmospheric $\mathrm{CO}_{2}$ variability, which in turn drives negative lagged sea-to-air flux variability by varying the sea-to-air $p \mathrm{CO}_{2}$ gradient.

\section{f. Carbon cycle response to ENSO}

So far, we have not considered which physical modes of climate variability are driving variability in the carbon system. Because the variances described above have peaks in the 3-6-yr band that is typically associated with ENSO, we focus on ENSO-related variability and examine detrended monthly anomalies of carbon cycle

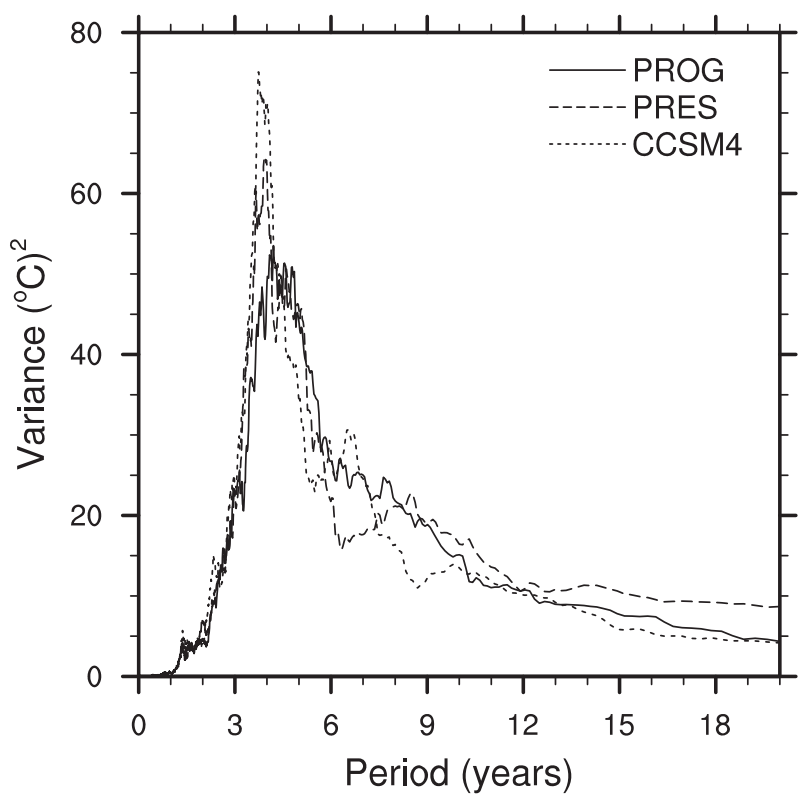

FIG. 10. Power spectra of detrended monthly anomalies of Niño 3.4 SST. Spectra is computed from years 1-1000 of each experiment.

related quantities and relate them to detrended monthly anomalies of SST in the Niño 3.4 region, an index related to ENSO.

To put the carbon cycle response in context, we first consider the power spectrum of Niño 3.4 SST anomalies. This diagnostic of the physical climate system is one of the few aspects of the model that is different between the CESM1(BGC) controls and CCSM4 (Fig. 10). In particular, the variance in the 3-6-yr band has a lower peak value and a broader shape in the CESM1(BGC) PRES control than in the CCSM4 control, resulting in a smaller variance in this band. This reduction in variance is consistent with the results of Jochum et al. (2010), who showed a reduction in ENSO variance in CCSM3 with the introduction of prognostic surface chlorophyll. During an El Niño event, equatorial upwelling is reduced, which reduces nutrient supply to the euphotic zone. This reduces surface chlorophyll, and when it is prognostic, leads to deeper penetration of shortwave radiation, cooling the surface, which reduces the ENSO SST anomaly. Jochum et al. (2010) identify this feedback process as a key mechanism in the ENSO variance reduction in CCSM3. Detailed analysis of this variance reduction in the CESM1(BGC) experiments is beyond the scope of this manuscript. The variance in the 3-6-yr band is also lower in the CESM1(BGC) PROG control than it is in the CESM1(BGC) PRES control. We do not have a physically motivated explanation for this difference and primarily point it out 
because surface carbon fluxes are responsive to this reduction in variance. A detailed analysis of the behavior of ENSO in CCSM4 is presented by Deser et al. (2012). Their analysis demonstrates that several characteristics of ENSO are better captured by CCSM4 than by CCSM3, including the period, now 3-6 years, and the amplitude and duration of events. Atmospheric teleconnections, which play a significant role in remote responses by the carbon system via remote changes in precipitation and temperature, are "generally well simulated" (Deser et al. 2012). Deficiencies in the simulation are that the overall magnitude of ENSO variability is larger than observed and the negative autocorrelation in the Niño 3.4 index at \pm 2 years is too large in magnitude. This later point indicates that the model is too likely to transition to a La Niña event after an El Niño event.

On the subannual time scales that are characteristic of ENSO event durations, the atmosphere does not completely mix tracers, leading to a nonuniform response of atmospheric $\mathrm{CO}_{2}$ to ENSO. So our analysis transitions from global means to local values. Sampling at Mauna Loa, Hawaii and Point Barrow, Alaska, we have computed the lagged correlation regression coefficient between monthly anomalies of SSTs in the Niño 3.4 region and atmospheric $\mathrm{CO}_{2}$ (Fig. 11). Notable features in the observations are an increase in atmospheric $\mathrm{CO}_{2}$ at both locations following an El Niño event, a larger response at Point Barrow than at Mauna Loa, and a phase difference in the response, with the peak response occurring later at Point Barrow. While the model does generate the increase in atmospheric $\mathrm{CO}_{2}$ following an El Niño event, the rate of change of the increase and its net magnitude, both normalized to the magnitude of the SST increase, are less than observed at both locations. This indicates an undersensitivity of the modeled carbon system to variations in physical forcing. Because the land model is the dominant source of this response, we attribute the weak atmospheric $\mathrm{CO}_{2}$ response to a weak response in the land-to-air $\mathrm{CO}_{2}$ fluxes. We do not know the cause of this weak response. While deficiencies in the land model likely contribute to the weak response, we cannot rule out a contribution from deficiencies in the climate model's simulation of ENSO. Disentangling these contributions would require further sensitivity experiments and analysis, a study that is beyond the scope of this manuscript. The model does not capture the difference in response magnitude at the two locations, and while the modeled response does have the phase lag that occurs in the observations, the peak response in the model occurs too early at both locations. The climate model's tendency to transition with greater regularity than indicated by observations to a La Niña
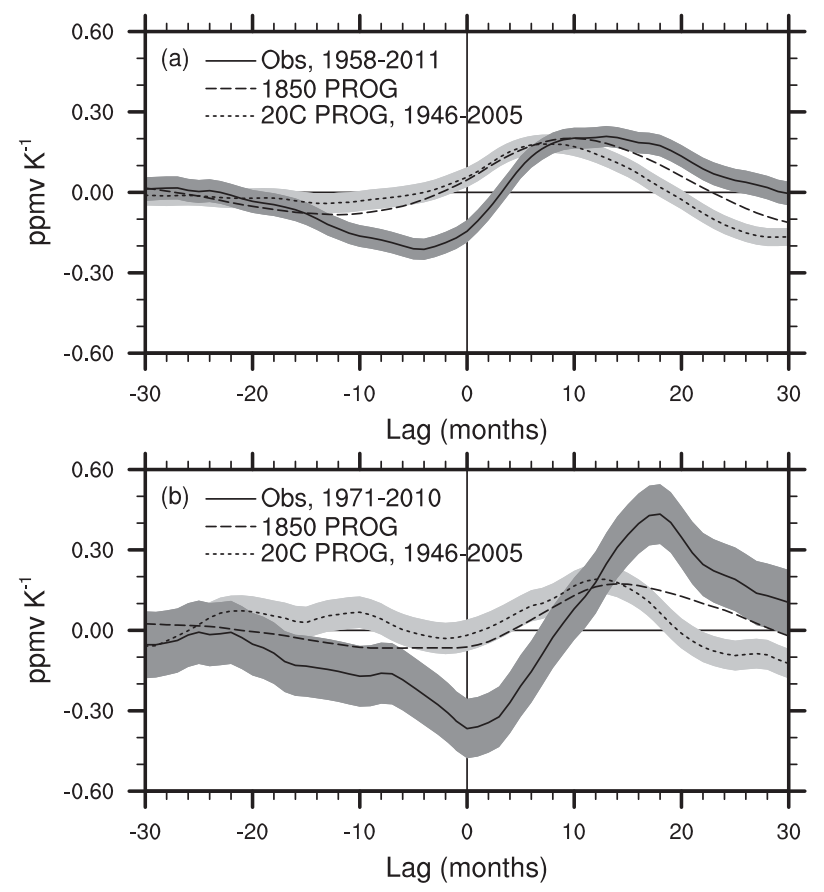

FIG. 11. Lagged correlation regression coefficient (slope) between detrended monthly anomalies of Niño 3.4 SSTs and atmospheric $\mathrm{CO}_{2}$ at (a) Mauna Loa, Hawaii and (b) Point Barrow, Alaska. Positive lags correspond to the SSTs leading. Shading denotes $95 \%$ confidence intervals of the regression coefficient. Observed monthly Niño 3.4 SSTs are from Extended Reconstructed SST, version $3 b$ (ERSST.V3B), from the National Oceanic and Atmospheric Administration (NOAA)'s Climate Prediction Center (www.cpc.ncep.noaa.gov/data/indices/). Observed monthly $\mathrm{CO}_{2}$ at Mauna Loa is from Dr. Pieter Tans, NOAA's Earth System Laboratory (ESRL) (www.esrl.noaa.gov/gmd/ccgg/trends/) and Dr. Ralph Keeling, Scripps Institution of Oceanography (scrippsco2. ucsd.edu/). Observed monthly $\mathrm{CO}_{2}$ at Point Barrow is from NOAA's Global Monitoring Division (www.esrl.noaa.gov/gmd/ ccgg/insitu.html).

event after an El Niño event likely plays a role in this mismatch.

Corresponding lagged correlation regression coefficients for the global land-to-air $\mathrm{CO}_{2}$ flux reveal that the land has a net release of $\mathrm{CO}_{2}$ in response to El Niño events and that the phasing and magnitude of this response is essentially unchanged with the introduction of prognostic $\mathrm{CO}_{2}$ (Fig. 12a). A regional breakdown of this response shows that it is geographically widespread (Fig. 12b). Except for Africa, the regional response is a slightly lagged release of carbon to the atmosphere. The lagged correlation regression coefficients for the global sea-to-air $\mathrm{CO}_{2}$ flux have the opposite sign of those for the land-to-air fluxes, are smaller in magnitude (Fig. 12c), and their subsequent effect on atmospheric $\mathrm{CO}_{2}$ is small. Additionally, the prognostic $\mathrm{CO}_{2}$ significantly enhances the response. The reason for this 
difference is again the coupling of the sea-to-air fluxes to the land-to-air fluxes via atmospheric $\mathrm{CO}_{2}$.

\section{g. Seasonal cycle of the carbon cycle}

We describe in this subsection the seasonal cycle of atmospheric $\mathrm{CO}_{2}$ and its surface fluxes. In the following, the mean and spread of the detrended seasonal cycle for various quantities are constructed from model monthly means as follows. First, detrended monthly anomalies are computed by subtracting from each monthly mean a centered 12-month running mean (i.e., a centered 13-month running mean where the end weights are onehalf of the remaining weights). This construction is used in order to remove interannual variability from the analysis. The mean detrended seasonal cycle for each month is then the average of that month's anomalies over all years in consideration. The spread for each month is the standard deviation of that month's anomalies. For brevity, we subsequently refer to these terms as the seasonal cycle and spread.

We compare the model's atmospheric $\mathrm{CO}_{2}$ to the observationally based product of the Cooperative Atmospheric Data Integration Project (2011), GLOBALVIEW$\mathrm{CO} 2$, sampling the model at four locations with long-term observational records: Point Barrow, Alaska; Mauna Loa, Hawaii; Palmer Station, Antarctica; and the South Pole (Fig. 13). Overall, the model does a reasonable job capturing the phasing of the seasonal cycle, evident in high correlation coefficients relative to the GLOBALVIEW product (Table 8). However, the model underestimates the amplitude of the seasonal cycle in the Northern Hemisphere. Using the atmospheric $\mathrm{CO}_{2}$ tracers that correspond to each $\mathrm{CO}_{2}$ flux component (land, ocean, and fossil fuels), we decompose the seasonal cycle in the net $\mathrm{CO}_{2}$ tracer into contributions from each component (Fig. 14; Table 8).

At Point Barrow, the modeled summer drawdown of $\mathrm{CO}_{2}$ occurs too early and is significantly weaker than the drawdown in the observations. This result is consistent with comparisons made by Keppel-Aleks et al. (2013) between CESM1(BGC) and column and aircraft $\mathrm{CO}_{2}$ measurements. Consistent with the analysis of R97, the land component is the primary contributor to the seasonal cycle in the model, though with a smaller fractional contribution in our study $(76.8 \%)$ than in R97 (91.2\%). Because of the dominance of the land contribution, we attribute a significant fraction of the bias in the seasonal cycle of $\mathrm{CO}_{2}$ to biases in the seasonal cycle of the land-to-air $\mathrm{CO}_{2}$ fluxes. Development versions of CLM, which include updates to the model's nitrogen cycle, photosynthesis parameterization, and hydrologic cycle, have a larger amplitude seasonal cycle of land-toair $\mathrm{CO}_{2}$ fluxes. We anticipate that this will reduce the
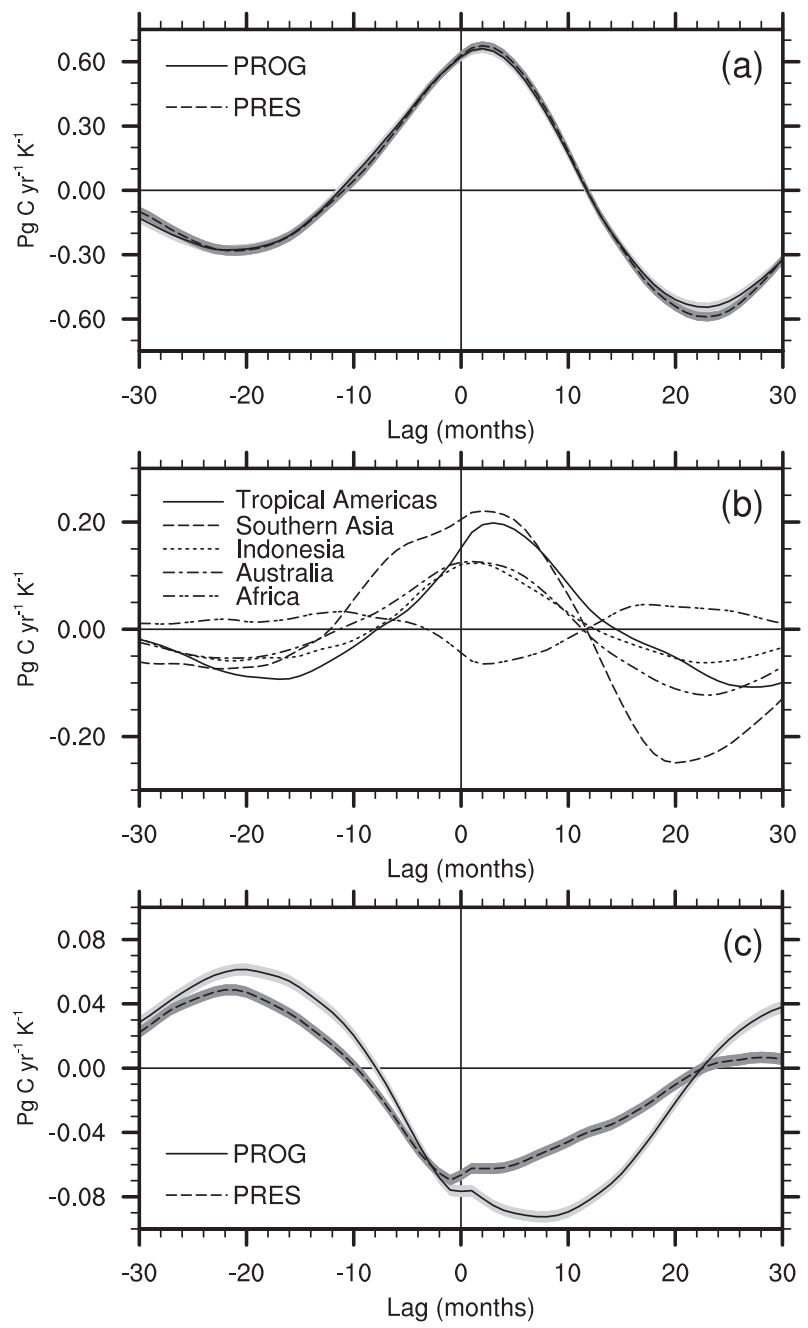

FIG. 12. Lagged correlation regression coefficient (slope) between detrended monthly anomalies of Niño 3.4 SSTs and (a) global land-to-air $\mathrm{CO}_{2}$ flux, (b) regional land-to-air $\mathrm{CO}_{2}$ flux, and (c) global sea-to-air $\mathrm{CO}_{2}$ flux. Positive lags correspond to the SSTs leading. Shading in (a) and (c) denotes $95 \%$ confidence intervals of the regression coefficient. Results are from the 1850 experiments (years 1-1000). Note that the vertical axis scales differ in the different panels.

bias in the seasonal cycle of $\mathrm{CO}_{2}$. We also point out that Levis et al. (2012) report improvements in the seasonal cycle of atmospheric $\mathrm{CO}_{2}$, diagnosed with an offline transport model, when seasonal crop phenology is included in CLM4CN.

The amplitude of the seasonal cycle of $\mathrm{CO}_{2}$ is noticeably larger in the $20 \mathrm{C}$ experiment than the $1850 \mathrm{ex}-$ periment, which is consistent with previous studies that have pointed out such an increase in the recent observational record (Keeling et al. 1996; Graven et al. 2013). The change in seasonal cycle of net $\mathrm{CO}_{2}$ can be decomposed into changes from each surface component. 

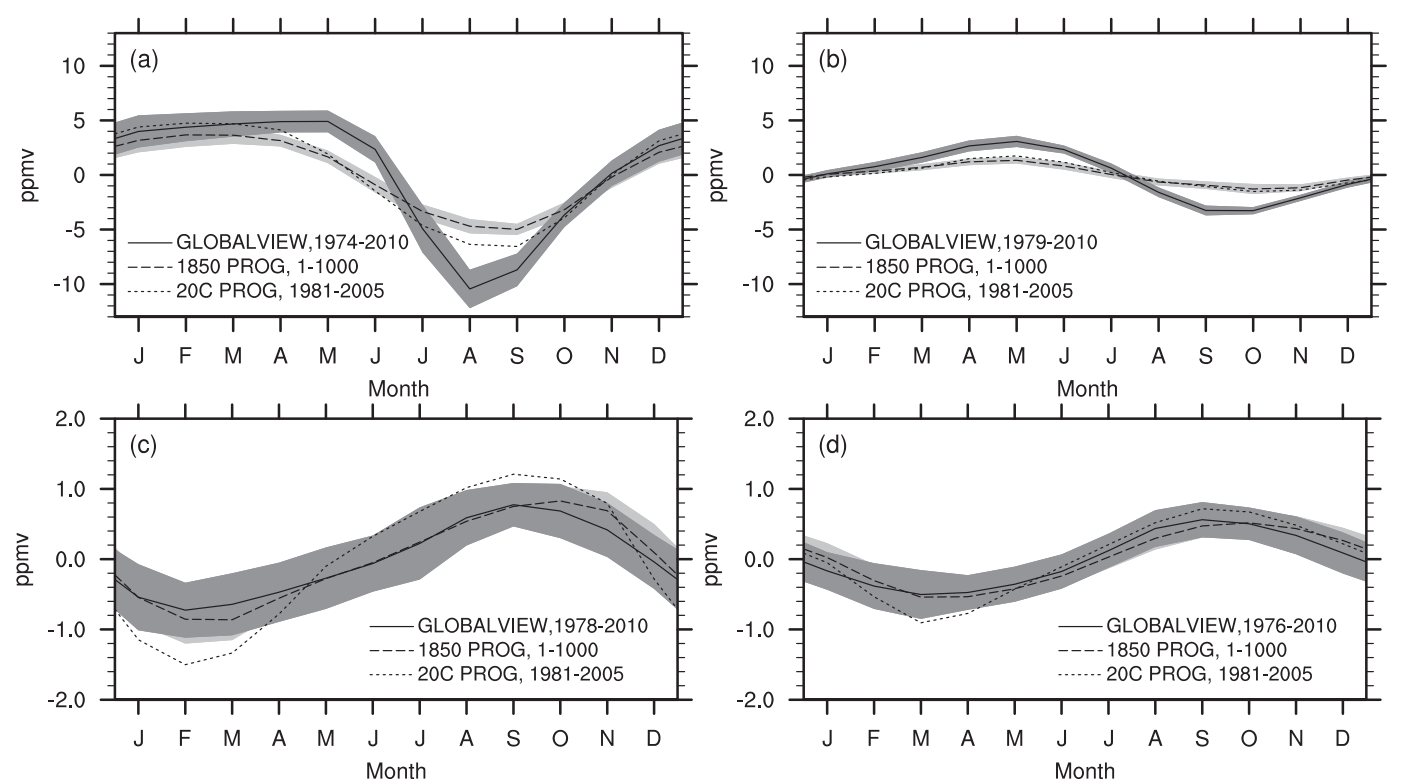

FIG. 13. Atmospheric $\mathrm{CO}_{2}$ seasonal cycle anomalies at (a) Point Barrow, Alaska; (b) Mauna Loa, Hawaii; (c) Palmer Station, Antarctica; and (d) the South Pole. Model results are from the grid point with the nearest location and elevation to the observing station. Shading denotes a \pm 2 standard deviation spread for the GLOBALVIEW (light gray) and 1850 (dark gray) values.

Quantifying the breakdown following R97, we find that the percentage contributions from the land, ocean, and fossil fuels are $46 \%, 17 \%$, and $37 \%$, respectively.

The results at Mauna Loa also show a low bias in the modeled seasonal cycle magnitude, while the modeled seasonal phasing is in good agreement with the observations. This would seem to indicate that the model deficiencies that cause the phasing mismatch at Point Barrow are confined to northern high latitudes. As at Point Barrow, the land component is the primary contributor to the seasonal cycle in the model $(81.6 \%)$, and the magnitude of its contribution agrees with the results of R97 (81.6\%). There is an increase in the magnitude of the seasonal cycle from the 1850 experiment to the $20 \mathrm{C}$ experiment, though its magnitude is smaller than that at Point Barrow. The percentage contributions to this change from the land, ocean, and fossil fuels are $54 \%$, $9 \%$, and $38 \%$, respectively.

The results at Palmer Station and the South Pole both show that while the 1850 experiment results are in good agreement with contemporary observations, this agreement degrades in the $20 \mathrm{C}$ results, particularly for the amplitude of the seasonal cycle. At these locations, particularly at Palmer Station, the ocean component is the largest contributor to the seasonal cycle in the model. While the results of R97 similarly show a larger ocean contribution at the southern high-latitudes sites than at the Northern Hemisphere sites, they still have the land component as the largest contributor at the
South Pole (they do not include Palmer Station in their analysis). Thus, there is a suggestion that a portion of the seasonal cycle bias is due to biases in the seasonal cycle of the sea-to-air $\mathrm{CO}_{2}$ fluxes. Excessively large zonal winds over the Southern Ocean in CCSM4, documented as a wind stress bias by Danabasoglu et al. (2012), likely play a role in this bias. There is an increase in the magnitude of the seasonal cycle from the 1850 experiment to the $20 \mathrm{C}$ experiment. The percentage contributions to this change from the land, ocean, and fossil fuels are $36 \%, 46 \%$, and $18 \%$, respectively, at Palmer Station and $9 \%, 43 \%$, and $47 \%$, respectively, at the South Pole.

Examination of the seasonal cycle magnitude beyond the four stations discussed above reveals large-scale

TABLE 8. Atmospheric $\mathrm{CO}_{2}$ seasonal cycle statistics for years 1981-2005 of the 20C PROG experiment. Land, ocean, and fossil fuel columns contain the percentage contribution of each surface component to net seasonal cycle, computed as in R97. "Corr" is the correlation coefficient between the mean modeled and GLOBALVIEW seasonal cycle, and normalized standard deviation (NSD) is the ratio of the model's spread to GLOBALVIEW's standard deviation.

\begin{tabular}{lccccc}
\hline \hline & & & \multicolumn{3}{c}{ Percent contribution } \\
\cline { 4 - 6 } \multicolumn{1}{c}{ Station } & Corr & NSD & Land & Ocean & Fossil fuel \\
\hline Point Barrow & 0.94 & 0.80 & 76.8 & 13.8 & 9.4 \\
Mauna Loa & 0.97 & 0.49 & 81.6 & 10.1 & 8.4 \\
Palmer Station & 0.97 & 1.87 & 18.3 & 71.7 & 10.1 \\
South Pole & 0.98 & 1.42 & 36.0 & 46.1 & 17.9 \\
\hline
\end{tabular}



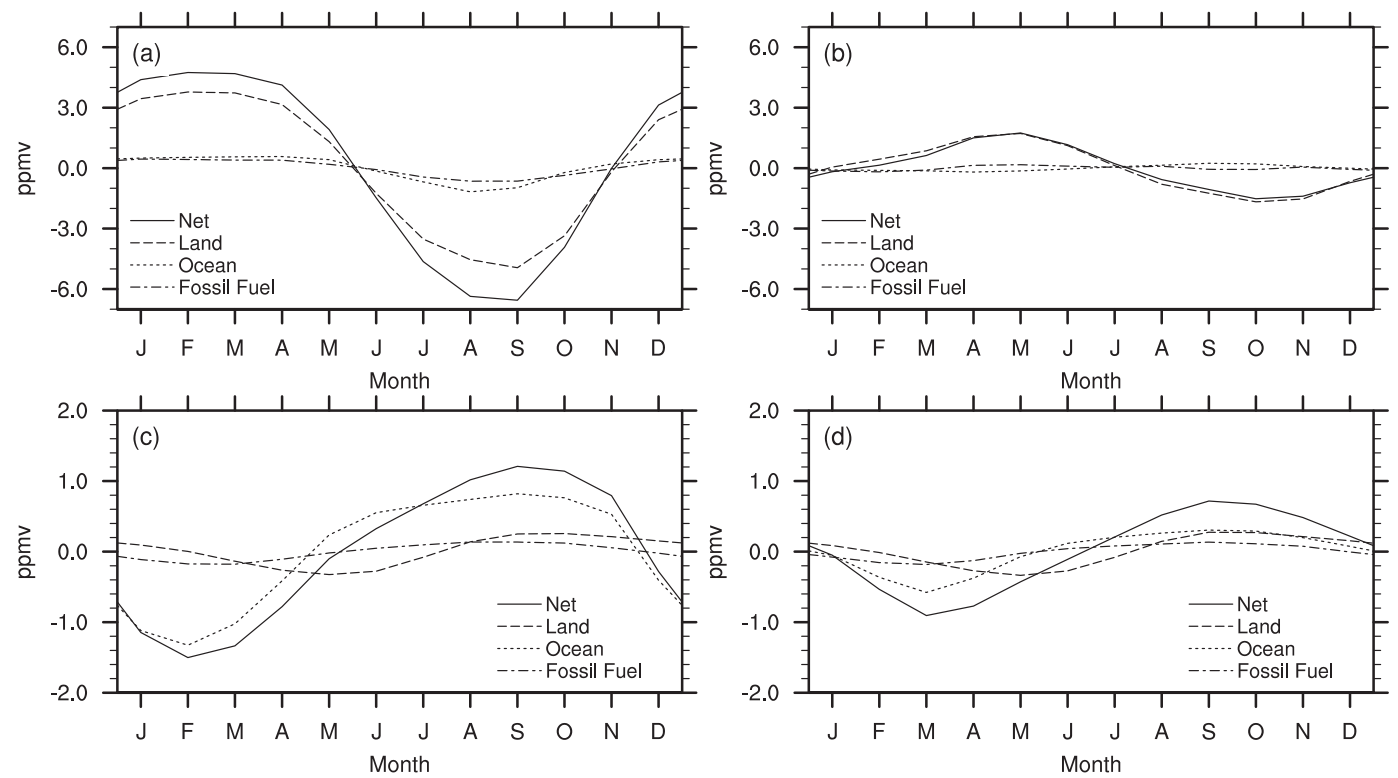

FIG. 14. Breakdown of modeled atmospheric $\mathrm{CO}_{2}$ seasonal cycle anomalies into surface components at (a) Point Barrow, Alaska; (b) Mauna Loa, Hawaii; (c) Palmer Station, Antarctica; and (d) the South Pole. Results are from the 20C PROG experiment (years 1981-2005).

spatial structure (Fig. 15). The magnitude of the seasonal cycle is largest over and near land regions with large productivity. The largest contributor to the seasonal cycle in these areas is the land. The ocean is the largest contributor over the Southern Ocean, and fossil fuels have a significant relative contribution over the tropical oceans. However, these are only larger roles in a relative sense. The absolute magnitude of their contributions is small compared to the land contribution in the Northern Hemisphere. The amplitude of the seasonal cycle is generally larger in the $20 \mathrm{C}$ experiment than in the 1850 experiment, particularly over northern Asia and eastern North America. Fossil fuels have the largest contribution to this increase over eastern Europe and the eastern United States, and the land has the largest contribution over eastern Asia, the Arctic, and eastern Canada.

The seasonal cycle of atmospheric $\mathrm{CO}_{2}$ is directly forced by the seasonal cycle of the $\mathrm{CO}_{2}$ fluxes provided by the surface components (Fig. 16). It is also influenced by atmospheric transport of $\mathrm{CO}_{2}$, an aspect of the seasonal cycle that we do not present an analysis of here. The seasonal cycle of the land-to-air $\mathrm{CO}_{2}$ fluxes (Fig. 16a) follows familiar patterns of net uptake in the summer, when productivity is larger than respiration, and net release in the winter, when the relative magnitude of these processes is reversed. The seasonal cycle of the sea-to-air $\mathrm{CO}_{2}$ fluxes (Fig. 16b) are the result of the superposition of a wider suite of processes: the seasonal cycle of productivity, temperature-driven solubility cycles, deep mixing in high latitudes exposing oversaturated water to the surface, and the influence of seasonal ice cover. Except for latitude bands where there is little land (e.g., over the Southern and Arctic Oceans), the amplitude of the seasonal cycle of the sea-to-air $\mathrm{CO}_{2}$ flux is much smaller than the land-toair's amplitude. The seasonal cycle of the fossil fuel emissions (Fig. 16c) is small and concentrated in the Northern Hemisphere.

In the PROG experiments, the seasonal cycle of atmospheric $\mathrm{CO}_{2}$ also affects the seasonal cycle of the surface $\mathrm{CO}_{2}$ fluxes through the usage of the prognostic $\mathrm{CO}_{2}$ concentrations in terrestrial photosynthesis and sea-to-air flux computations (Fig. 17). For the land $\mathrm{CO}_{2}$ fluxes, the difference in seasonal cycle between the PROG and PRES experiments is small compared to both the magnitude of the fluxes themselves and their standard deviation (not shown). The difference is less than one-fourth of the standard deviation for all months and latitude bands. While such a relative difference is statistically significant at the 0.95 level for the 1000 -yr-long 1850 experiments, it is not statistically significant over 100 years, much less over the 25 -yr period being presented from the $20 \mathrm{C}$ experiments. For the ocean $\mathrm{CO}_{2}$ fluxes, the difference shows a coherent structure that is linked to the seasonal cycle of surface atmospheric $\mathrm{CO}_{2}$, low summer surface atmospheric $\mathrm{CO}_{2}$ driving a flux anomaly from the sea to the air, and is modulated by the wind speed dependence of the flux and the influence of ice cover. While the difference is small compared to the 
(a)

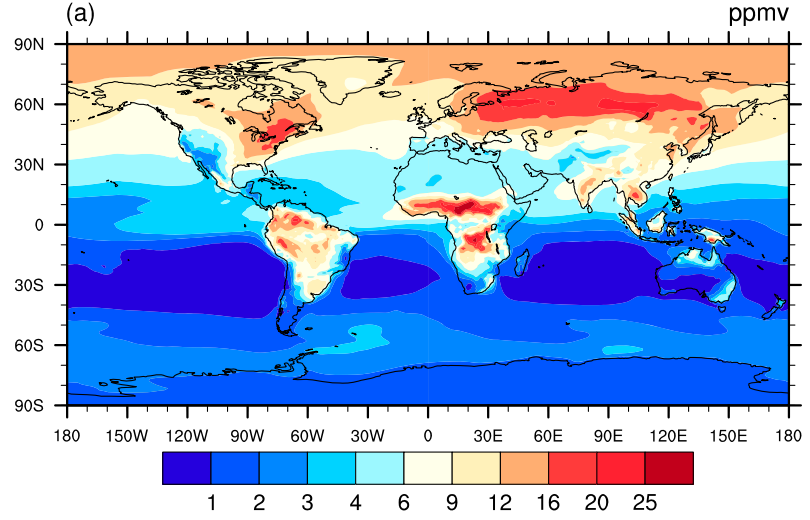

(b)

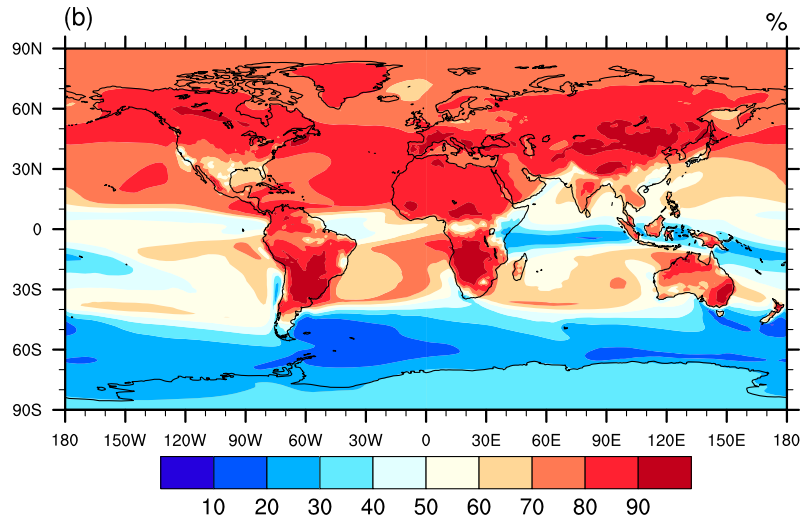

(c)

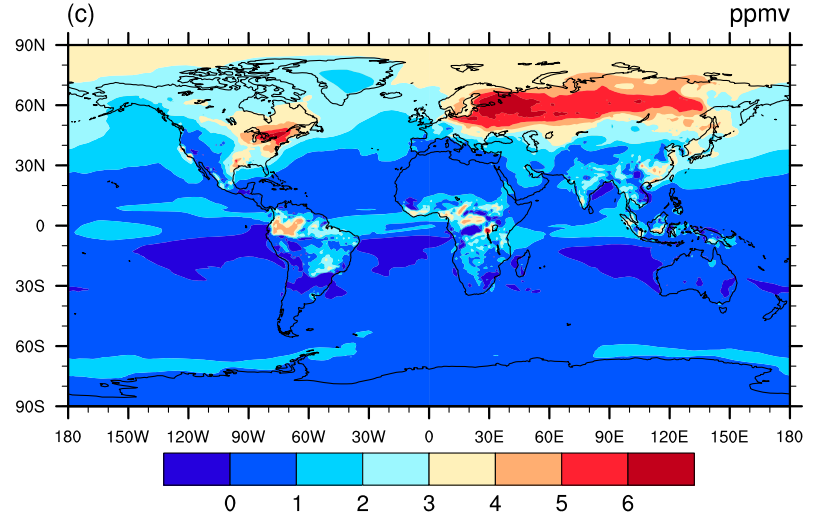

FIG. 15. Surface $\mathrm{CO}_{2}$ seasonal cycle, (a) amplitude from the $20 \mathrm{C}$ PROG experiment (years 1981-2005), (b) percentage contribution from the land component in the $20 \mathrm{C}$ experiment, and (c) the difference between the 20C and 1850 PROG experiments' amplitudes (years 1-1000). Note the nonlinear scale in (a).

magnitude of the fluxes themselves, it is comparable in magnitude to their standard deviation in many locations. For the 1000 -yr-long 1850 experiments, the difference is statistically significant at the 0.95 level nearly everywhere. The same relative difference over the 25 -yr period being presented from the $20 \mathrm{C}$ experiments is statistically significant in northern midlatitudes in the winter and summer months.
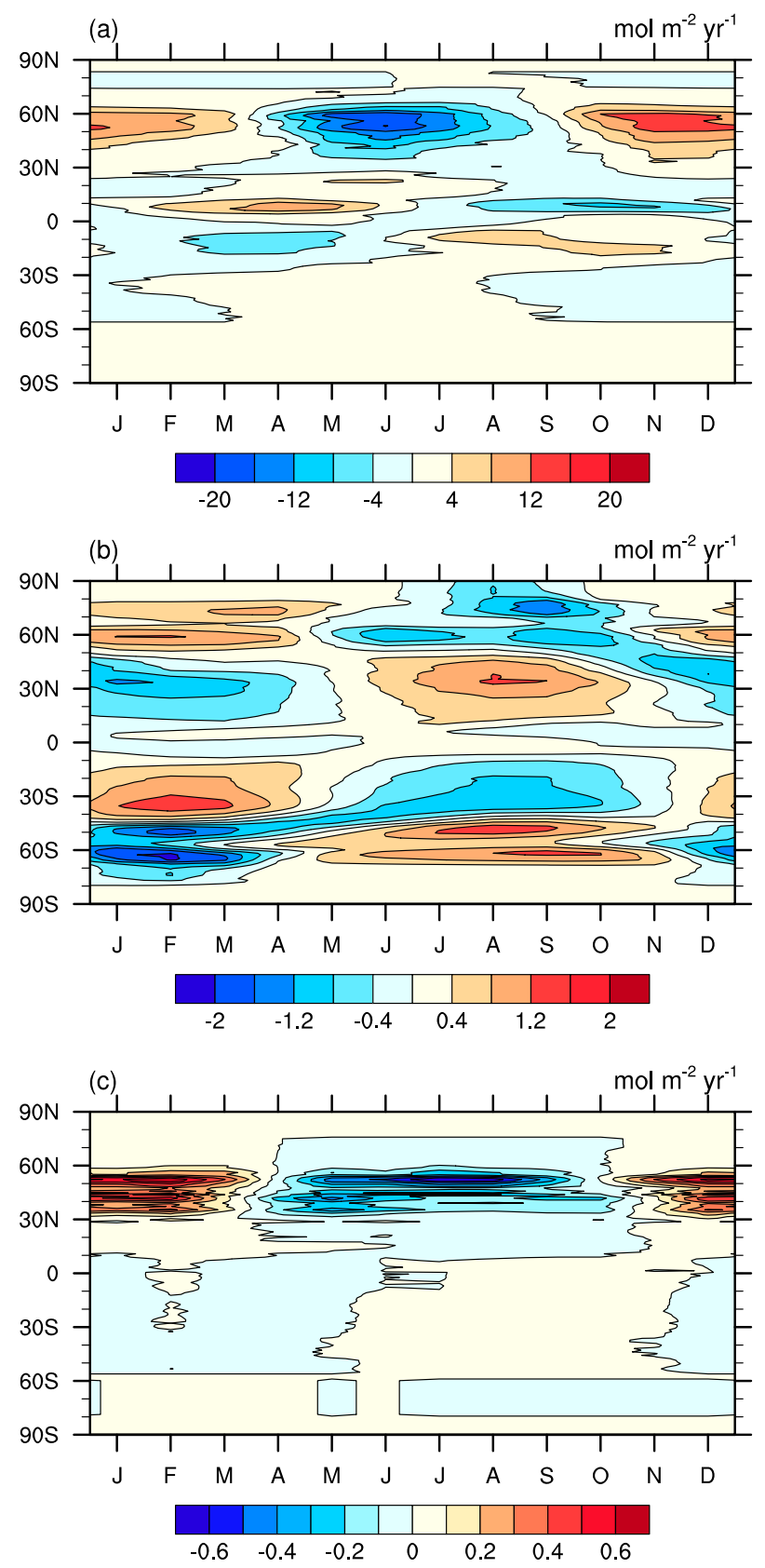

FIG. 16. Seasonal cycle of zonal mean of surface flux of $\mathrm{CO}_{2}$ to the atmosphere for (a) land, (b) ocean, and (c) fossil fuels. Fluxes are averaged in each latitude band over the entire band, not just the portion where the flux is nonzero. Results are from the 20C PROG experiment (years 1981-2005). Note that the fluxes are detrended and thus have their annual mean removed.

\section{Summary and conclusions}

We have documented the CESM1(BGC), an extension of CCSM4 that incorporates a full carbon cycle. We have provided a description of the model, detailed how preindustrial-control and twentieth-century experiments 

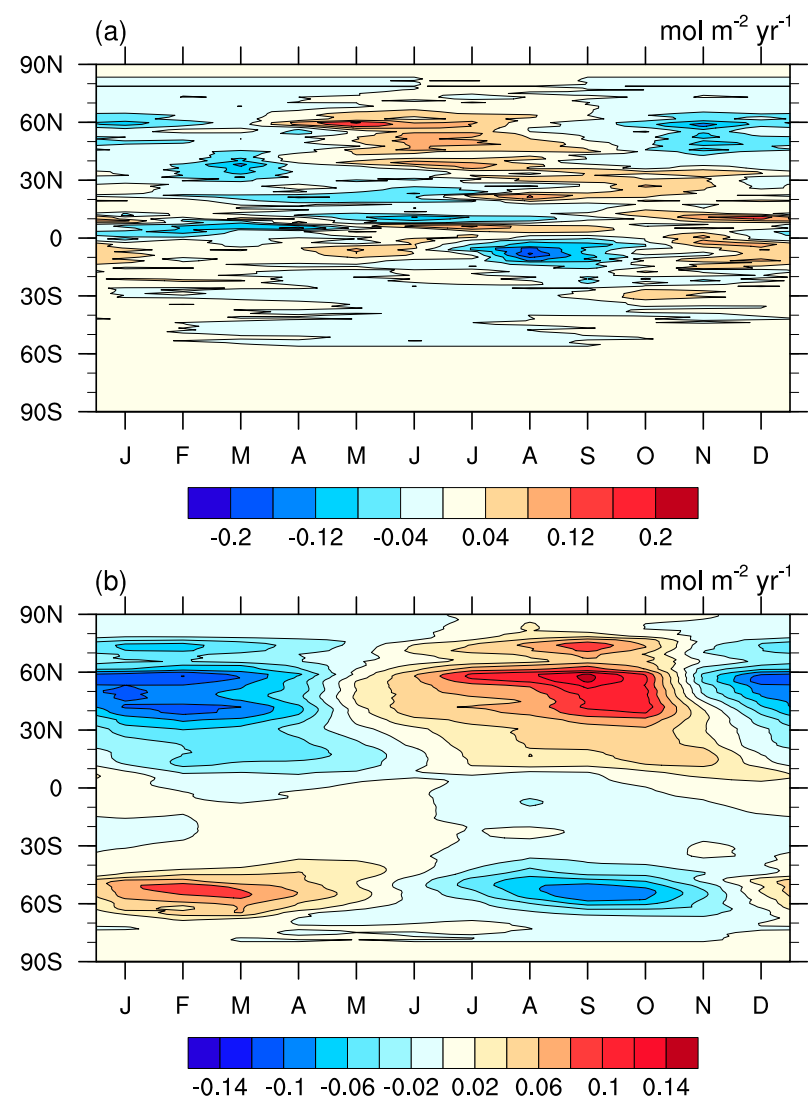

FIG. 17. Impact of prognostic $\mathrm{CO}_{2}$ (experiment PROG minus experiment PRES) on seasonal cycle of zonal mean of the (a) landto-air and (b) sea-to-air $\mathrm{CO}_{2}$ fluxes. Results are from the 1850 PROG and PRES experiments (years 1-1000).

were initialized and forced, and examined the behavior of the carbon cycle in those experiments. Our analysis of the experiments includes an examination of the factors governing the net increase of atmospheric $\mathrm{CO}_{2}$ in the twentieth century that results from fossil fuel and landuse emissions. We have analyzed how atmospheric $\mathrm{CO}_{2}$ and its surface fluxes vary on interannual time scales, including how they respond to ENSO, and described the seasonal cycle of atmospheric $\mathrm{CO}_{2}$ and its surface fluxes. While the model broadly reproduces observed aspects of the carbon cycle, there are several notable biases. The model-predicted increase in atmospheric $\mathrm{CO}_{2}$ over the twentieth century is too large. When atmospheric $\mathrm{CO}_{2}$ is a model prognostic quantity, it is too high in 2005 by $\sim 20$ ppmv. This bias is caused by a net release of $\mathrm{CO}_{2}$ from the land that is too large and an uptake of $\mathrm{CO}_{2}$ by the ocean that is too small. The land-to-air $\mathrm{CO}_{2}$ flux bias is larger in magnitude than the ocean uptake bias (Table 4). A challenge with reducing in future model versions the land-to-air flux bias is that it is difficult to decompose the integrated bias into components from land use emissions and a residual land uptake. The difficulty arises because of large uncertainties in the historical emissions from land-use change. That said, over the late-twentieth-century, comparison of the model to results of Canadell et al. (2007) suggests that the dominant term in the bias appears to be a bias in the residual land uptake (Figs. 3, 4).

The model's response of atmospheric $\mathrm{CO}_{2}$ to ENSO is too weak (Fig. 11). Though we do not currently know the mechanisms that cause this weak response, it is most likely due to an undersensitivity of the modeled carbon system to variations in physical forcing, particularly in the land model.

The seasonal cycle of atmospheric $\mathrm{CO}_{2}$ in the Northern Hemisphere is too small in amplitude, and the seasonal drawdown of $\mathrm{CO}_{2}$ begins too early at high northern latitudes (Fig. 13). This bias is due to deficiencies in the land-to-air $\mathrm{CO}_{2}$ fluxes and appears to be reduced in development versions of CLM.

These biases can be further summarized by stating that the model has a weak response to climatic variations on interannual and seasonal time scales, and to twentieth-century anthropogenic forcings, including rising atmospheric $\mathrm{CO}_{2}$, and atmospheric deposition of nitrogen. Research is ongoing to enhance our understanding of this aspect of the model's behavior (R. Q. Thomas et al. 2012, unpublished manuscript).

Beyond reducing model biases in this category, model development is ongoing to enhance existing and add additional features to CESM (BGC). Notable land developments include revising the photosynthesis parameterizations, resolving soil biogeochemistry vertically, and introducing permafrost dynamics. Notable ocean model developments include reducing the oxygen minimum extent bias, reducing the Southern Ocean ventilation bias, introducing effects of ocean acidification into the model, and enhancing ecosystem behavior with respect to sea ice. Model developments that span both components include parameterizing the global methane cycle, introducing global carbon isotopes, and coupling the individual nitrogen cycle modules to each other, yielding a fully coupled nitrogen cycle. These developments have the potential to directly improve model biogeochemical dynamics (in contemporary and projected climates), enhance the understanding of these dynamics, and make the model a useful tool to a broader community with its new capabilities.

Acknowledgments. We thank the editor and three anonymous reviewers for helpful comments and suggestions. The CESM project is supported by the National Science Foundation and the Office of Science (BER) of the U.S. Department of Energy. Computing 
resources were provided by the Climate Simulation Laboratory at NCAR's Computational and Information Systems Laboratory (CISL), sponsored by the National Science Foundation and other agencies. This research was enabled by CISL compute and storage resources. SCD acknowledges support from the National Science Foundation (NSF AGS-1048827). This research is supported in part by the U.S. Department of Energy (DOE), Office of Science, Biological and Environmental Research. Oak Ridge National Laboratory is managed by UT-BATTELLE for DOE under contract DE-AC05-00OR22725.

\section{REFERENCES}

Anav, A., and Coauthors, 2013: Evaluating the land and ocean components of the global carbon cycle in the CMIP5 Earth system models. J. Climate, 26, 6801-6843, doi:10.1175/ JCLI-D-12-00417.1.

Armstrong, R. A., C. Lee, J. I. Hedges, S. Honjo, and S. G. Wakeham, 2001: A new, mechanistic model for organic carbon fluxes in the ocean based on the quantitative association of POC with ballast minerals. Deep-Sea Res. II, 49, 219-236, doi:10.1016/S0967-0645(01)00101-1.

Arora, V. K., and Coauthors, 2013: Carbon-concentration and carbon-climate feedbacks in CMIP5 Earth system models. J. Climate, 26, 5289-5314, doi:10.1175/JCLI-D-12-00494.1.

Bonan, G. B., and S. Levis, 2010: Quantifying carbon-nitrogen feedbacks in the Community Land Model (CLM4). Geophys. Res. Lett., 37, L07401, doi:10.1029/2010GL042430.

Bousquet, P., P. Peylin, P. Ciais, C. L. Quéré, P. Friedlingstein, and P. P. Tans, 2000: Regional changes in carbon dioxide fluxes of land and oceans since 1980. Science, 290, 1342-1346, doi:10.1126/science.290.5495.1342.

Brohan, P., J. J. Kennedy, I. Harris, S. F. B. Tett, and P. D. Jones, 2006: Uncertainty estimates in regional and global observed temperature changes: A new data set from 1850. J. Geophys. Res., 111, D12106, doi:10.1029/2005JD006548.

Cadule, P., P. Friedlingstein, L. Bopp, S. Sitch, C. D. Jones, P. Ciais, S. L. Piao, and P. Peylin, 2010: Benchmarking coupled climate-carbon models against long-term atmospheric $\mathrm{CO}_{2}$ measurements. Global Biogeochem. Cycles, 24, GB2016, doi:10.1029/2009GB003556.

Canadell, J. G., and Coauthors, 2007: Contributions to accelerating atmospheric $\mathrm{CO}_{2}$ growth from economic activity, carbon intensity, and efficiency of natural sinks. Proc. Natl. Acad. Sci. USA, 104, 18 866-18 870, doi:10.1073/pnas.0702737104.

Carr, M.-E., and Coauthors, 2006: A comparison of global estimates of marine primary production from ocean color. DeepSea Res. II, 53, 741-770, doi:10.1016/j.dsr2.2006.01.028.

Cooperative Atmospheric Data Integration Project, 2011: GLOBALVIEW-CO2, NOAA ESRL, CD-ROM.

Danabasoglu, G., S. C. Bates, B. P. Briegleb, S. R. Jayne, M. Jochum, W. G. Large, S. Peacock, and S. G. Yeager, 2012: The CCSM4 ocean component. J. Climate, 25, 1361-1389, doi:10.1175/ JCLI-D-11-00091.1.

Deser, C., and Coauthors, 2012: ENSO and Pacific decadal variability in Community Climate System Model version 4. J. Climate, 25, 2622-2651, doi:10.1175/JCLI-D-11-00301.1.

Doney, S. C., K. Lindsay, I. Fung, and J. John, 2006: Natural variability in a stable, 1000-yr global coupled climate-carbon cycle simulation. J. Climate, 19, 3033-3054, doi:10.1175/ JCLI3783.1.

— I. Lima, R. A. Feely, D. M. Glover, K. Lindsay, N. Mahowald, J. K. Moore, and R. Wanninkhof, 2009: Mechanisms governing interannual variability in upper-ocean inorganic carbon system and air-sea $\mathrm{CO}_{2}$ fluxes: Physical climate and atmospheric dust. Deep-Sea Res. II, 56, 640-655, doi:10.1016/ j.dsr2.2008.12.006.

Friedlingstein, P., and Coauthors, 2006: Climate-carbon cycle feedback analysis: Results from the C4MIP model intercomparison. J. Climate, 19, 3337-3353, doi:10.1175/JCLI3800.1.

Fung, I. Y., S. C. Doney, K. Lindsay, and J. John, 2005: Evolution of carbon sinks in a changing climate. Proc. Natl. Acad. Sci. USA, 102, 11 201-11 206, doi:10.1073/pnas.0504949102.

Galloway, J. N., and Coauthors, 2004: Nitrogen cycles: Past, present, and future. Biogeochemistry, 70, 153-226, doi:10.1007/ s10533-004-0370-0.

Garcia, H. E., R. A. Locarnini, T. P. Boyer, J. I. Antonov, O. K. Baranova, M. M. Zweng, and D. R. Johnson, 2010: Dissolved Oxygen, Apparent Oxygen Utilization, and Oxygen Saturation. Vol. 3, World Ocean Atlas 2009, NOAA Atlas NESDIS 70, 28 pp.

Gent, P. R., and Coauthors, 2011: The Community Climate System Model version 4. J. Climate, 24, 4973-4991, doi:10.1175/ 2011JCLI4083.1.

Graven, H. D., and Coauthors, 2013: Enhanced seasonal exchange of $\mathrm{CO}_{2}$ by northern ecosystems since 1960 . Science, 341, 10851089, doi:10.1126/science.1239207.

Hoffman, F. M., and Coauthors, 2014: Causes and implications of persistent atmospheric carbon dioxide biases in Earth system models. J. Geophys. Res. Biogeosci., 119, 141-162, doi:10.1002/ 2013JG002381.

Holzer, M., 1999: Analysis of passive tracer transport as modeled by an atmospheric general circulation model. J. Climate, 12, 1659-1684, doi:10.1175/1520-0442(1999)012<1659: AOPTTA $>2.0 . \mathrm{CO} ; 2$.

Houghton, R. A., 2003: Revised estimates of the annual net flux of carbon to the atmosphere from changes in land use and land management 1850-2000. Tellus, 55B, 378-390, doi:10.1034/ j.1600-0889.2003.01450.x.

Hurrell, J. W., and Coauthors, 2013: The Community Earth System Model: A framework for collaborative research. Bull. Amer. Meteor. Soc., 94, 1339-1360, doi:10.1175/BAMS-D-12-00121.1.

Hurtt, G. C., S. Frolking, M. G. Fearon, B. Moore, E. Shevliakova, S. Malyshev, S. W. Pacala, and R. A. Houghton, 2006: The underpinnings of land-use history: Three centuries of global gridded land-use transitions, wood-harvest activity, and resulting secondary lands. Global Change Biol., 12, 1208-1229, doi:10.1111/j.1365-2486.2006.01150.x.

Jochum, M., S. Yeager, K. Lindsay, K. Moore, and R. Murtugudde, 2010: Quantification of the feedback between phytoplankton and ENSO in the Community Climate System Model. J. Climate, 23, 2916-2925, doi:10.1175/2010JCLI3254.1.

Keeling, C. D., J. F. S. Chin, and T. P. Whorf, 1996: Increased activity of northern vegetation inferred from atmospheric $\mathrm{CO}_{2}$ measurements. Nature, 382, 146-149, doi:10.1038/382146a0.

Keppel-Aleks, G., and Coauthors, 2013: Atmospheric carbon dioxide variability in the Community Earth System Model: Evaluation and transient dynamics during the twentieth and twenty-first centuries. J. Climate, 26, 4447-4475, doi:10.1175/ JCLI-D-12-00589.1.

Khatiwala, S., F. Primeau, and T. Hall, 2009: Reconstruction of the history of anthropogenic $\mathrm{CO}_{2}$ concentrations in the ocean. Nature, 462, 346-349, doi:10.1038/nature08526. 
Koven, C. D., and Coauthors, 2013: The effect of vertically resolved soil biogeochemistry and alternate soil $\mathrm{C}$ and $\mathrm{N}$ models on C dynamics of CLM4. Biogeosciences, 10, 7109-7131, doi:10.5194/bg-10-7109-2013.

Krinner, G., and Coauthors, 2005: A dynamic global vegetation model for studies of the coupled atmosphere-biosphere system. Global Biogeochem. Cycles, 19, GB1015, doi:10.1029/ 2003 GB002199.

Krishnamurthy, A., J. K. Moore, C. S. Zender, and C. Luo, 2007: Effects of atmospheric inorganic nitrogen deposition on ocean biogeochemistry. J. Geophys. Res., 112, G02019, doi:10.1029/ 2006JG000334.

Lamarque, J.-F., and Coauthors, 2010: Historical (1850-2000) gridded anthropogenic and biomass burning emissions of reactive gases and aerosols: Methodology and application. Atmos. Chem. Phys., 10, 7017-7039, doi:10.5194/acp-10-7017-2010.

Lawrence, D. M., and Coauthors, 2011: Parameterization improvements and functional and structural advances in version 4 of the Community Land Model. J. Adv. Model. Earth Syst., 3, M03001, doi:10.1029/2011MS000045.

_ , K. W. Oleson, M. G. Flanner, C. G. Fletcher, P. J. Lawrence, S. Levis, S. C. Swenson, and G. B. Bonan, 2012: The CCSM4 land simulation, 1850-2005: Assessment of surface climate and new capabilities. J. Climate, 25, 2240-2260, doi:10.1175/ JCLI-D-11-00103.1.

Lawrence, P. J., and Coauthors, 2012: Simulating the biogeochemical and biogeophysical impacts of transient land cover change and wood harvest in the Community Climate System Model (CCSM4) from 1850 to 2100. J. Climate, 25 , 3071-3095, doi:10.1175/JCLI-D-11-00256.1.

Levis, S., G. B. Bonan, E. Kluzek, P. E. Thornton, A. Jones, W. J. Sacks, and C. J. Kucharik, 2012: Interactive crop management in the Community Earth System Model (CESM1): Seasonal influences on land-atmosphere fluxes. J. Climate, 25, 48394859, doi:10.1175/JCLI-D-11-00446.1.

Long, M. C., K. Lindsay, S. Peacock, J. K. Moore, and S. C. Doney, 2013: Twentieth-century oceanic carbon uptake and storage in CESM1(BGC). J. Climate, 26, 6775-6800, doi:10.1175/ JCLI-D-12-00184.1.

Luo, C., N. M. Mahowald, and J. del Corral, 2003: Sensitivity study of meteorological parameters on mineral aerosol mobilization, transport, and distribution. J. Geophys. Res., 108, 4447, doi:10.1029/2003JD003483.

Moore, J. K., and S. C. Doney, 2007: Iron availability limits the ocean nitrogen inventory stabilizing feedbacks between marine denitrification and nitrogen fixation. Global Biogeochem. Cycles, 21, GB2001, doi:10.1029/2006GB002762.

- and O. Braucher, 2008: Sedimentary and mineral dust sources of dissolved iron to the world ocean. Biogeosciences, 5, 631656, doi:10.5194/bg-5-631-2008.
— S. C. Doney, and K. Lindsay, 2004: Upper ocean ecosystem dynamics and iron cycling in a global three-dimensional model. Global Biogeochem. Cycles, 18, GB4028, doi:10.1029/ 2004GB002220.

, K. Lindsay, S. C. Doney, M. C. Long, and K. Misumi, 2013: Marine ecosystem dynamics and biogeochemical cycling in the Community Earth System Model [CESM1(BGC)]: Comparison of the 1990s with the 2090s under the RCP4.5 and RCP8.5 scenarios. J. Climate, 26, 9291-9312, doi:10.1175/ JCLI-D-12-00566.1.

Randerson, J. T., M. V. Thompson, T. J. Conway, I. Y. Fung, and C. B. Field, 1997: The contribution of terrestrial sources and sinks to trends in the seasonal cycle of atmospheric carbon dioxide. Global Biogeochem. Cycles, 11, 535-560, doi:10.1029/ 97GB02268.

— geochemistry in coupled climate-carbon models. Global Change Biol., 15, 2462-2484, doi:10.1111/j.1365-2486.2009.01912.x.

Sabine, C. L., and Coauthors, 2004: The oceanic sink for anthropogenic $\mathrm{CO}_{2}$. Science, 305, 367-371, doi:10.1126/ science.1097403.

Thornton, P. E., J.-F. Lamarque, N. A. Rosenbloom, and N. M. Mahowald, 2007: Influence of carbon-nitrogen cycle coupling on land model response to $\mathrm{CO}_{2}$ fertilization and climate variability. Global Biogeochem. Cycles, 21, GB4018, doi:10.1029/ 2006GB002868.

, and Coauthors, 2009: Carbon-nitrogen interactions regulate climate-carbon cycle feedbacks: Results from an atmosphereocean general circulation model. Biogeosciences, 6, 20992120, doi:10.5194/bg-6-2099-2009.

Todd-Brown, K. E. O., J. T. Randerson, W. M. Post, F. M. Hoffman, C. Tarnocai, E. A. G. Schuur, and S. D. Allison, 2013: Causes of variation in soil carbon simulations from CMIP5 Earth system models and comparison with observations. Biogeosciences, 10, 1717-1736, doi:10.5194/bg-10-1717-2013.

Wang, S., J. K. Moore, F. W. Primeau, and S. Khatiwala, 2012: Simulation of anthropogenic $\mathrm{CO}_{2}$ uptake in the CCSM3.1 ocean circulation-biogeochemical model: Comparison with data-based estimates. Biogeosciences, 9, 1321-1336, doi:10.5194/ bg-9-1321-2012.

Wang, Y. P., R. M. Law, and B. Pak, 2010: A global model of carbon, nitrogen and phosphorus cycles for the terrestrial biosphere. Biogeosciences, 7, 2261-2282, doi:10.5194/ bg-7-2261-2010.

Zaehle, S., A. D. Friend, P. Friedlingstein, F. Dentener, P. Peylin, and M. Schulz, 2010: Carbon and nitrogen cycle dynamics in the O-CN land surface model: 2. Role of the nitrogen cycle in the historical terrestrial carbon balance. Global Biogeochem. Cycles, 24, GB1006, doi:10.1029/ 2009 GB003522. 